\title{
REDES POLISÉMICAS Y NIVELES DE INTERPRETACIÓN. REPRESENTACIÓN SEMÁNTICA DE UNIDADES LINGÜÍSTICAS COMPLEJAS: EL CASO DE VAMOS
}

\author{
FERnANDO POLANCO MARTíneZ \\ Universidad de Barcelona \\ polanco@ub.edu
}

Resumen

La polifuncionalidad de marcadores funcionalmente complejos como vamos no se reduce a la mera variación contextual a partir de un único significado invariante, sino que revela, más bien, su naturaleza heterosémica, esto es, polisémica y policategorial. Estos elementos complejos presentan más de un significado convencional asociado a determinadas funciones discursivo-interactivas con rasgos gramaticales y semántico-pragmáticos estables diferenciados, así como varios sentidos contextuales con distinto grado de prominencia derivados de la interacción de los significados codificados con determinados contextos. Por ello, para el tratamiento semántico-funcional de esta unidad discursiva, en este trabajo proponemos un modelo polisémico radial (Lakoff, 1987; Hansen, 2005; Evans, 2004, 2006). Creemos que un modelo polisémico de este tipo permite describir y explicar adecuadamente (i) la variabilidad categorial, semántica y funcional de unidades discursivas complejas como vamos; (ii) los vínculos que existen entre los distintos usos de estas unidades; y, en definitiva, (iii) la estructura gramático-funcional subyacente de estos elementos.

PALABRAS CLAVE: Marcadores del discurso, Partículas discursivas, Pragmática, Semántica cognitiva, Gramática interaccional.
Abstract

The polifunctionality of complex discoursive markers like Spanish conversational particle vamos can not be reduced to contextual variation from a single invariant meaning. It reveals, rather, the heterosemic nature of this linguistic unit, that is, polysemous and polycategorial character. These kind of complex units present more than one conventional meaning linked to particular discoursiveinteractive functions whith stable grammatical, semantic and pragmatic treats, as well as several contextual senses with degrees of cognitive prominence derived from interaction of coded meanings with particular contexts. Because of that, for treating the semantics of this linguistic unit, in this paper we propose a model of polysemy network (Lakoff, 1987; Hansen, 2005; Evans, 2004, 2006). We hold that such a model allows to adequately describe and explain (i) the categorial, semantic and functional variability of complex linguistic units like vamos; (ii) the ties between the different uses of these kind of units; and (iii), in short, the grammatical and functional structure underlying them.

KEY WORDS: Discourse markers, Discoursive particles, Pragmatics, Cognitive Semantics, Interactional Grammar. 


\section{Introducción}

La expansión funcional que caracteriza a muchos marcadores discursivos, especialmente a los llamados marcadores conversacionales (Martín Zorraquino y Portolés, 1999), suele ir acompañada también de una consecuente ampliación de los valores semánticos de estas unidades. La casuística semántico-funcional de estos elementos es variada y supone generalmente un reto especificar la relación entre sus distintos usos y los valores semánticos derivados. El caso de vamos no constituye una excepción y representa un buen ejemplo de lo anterior:

(1) O sea, en su momento, hubo tesis por las cuales el segundo canal iba a ser un canal que se podría haber financiado sin publicidad, vamos a costa del presupuesto, [...]. (CREA; Debate: las nuevas televisiones, 10/12/87, TVE 1)

(2) (...) luego viene Daniel, que Daniel es muy curioso $<$ PAUSE $>$ bueno, tiene catorce años, es el pequeño de los niños, pero tiene un espabile encima, vamos, que ese sí que no parece que tiene catorce años porque es demasiado espabilado, se pasa de rosca, pero es supergracioso, nos partimos con él. (CREA; Entrevista CSC008, mujer, 20 años)

(3) [...] es que bueno, por no hacer muy extensiva la intervención en cuanto a los grupos, vamos, en cuanto a los factores de riesgo. (CREA; Debate: El Sida, 23/04/87, TVE 1)

(4) y el de la autoescuela le dice pero tío pero ¿¡de qué vas \!? ¿¡tú estás loco!?/ ¿cómo te vas-? si acabas de empeZAAR $\downarrow$ no has venío ningún día a clase/ vamos o s(e)a// yo si quieres yo te apunto// tú eres el que vas a tener QUE PAGAR/ que me apuntes $\downarrow$ que me apuntes $\downarrow$ que me apuntes $\downarrow$ que me apuntes $\downarrow$ es cantidad de cabezón $\downarrow$ que me apuntes $\downarrow$ total quee lo puso de tal forma que lo tuvo que apuntar// yy ¿cuándo fue eel-? sí $\downarrow$ el- el martes pasado $\downarrow$ creo que fue examen (Briz y grupo Val.Es.Co, 2002: 113 [L.15.A.2])

(5) A: ¿yy alguna fiesta del barrio?// ¿de cuando eras pequeña?

B: yo no he ido- no he sido muy de barrio (chasquido)// pero vamos recuerdo las Fallas sobre todo las Fallas// es cuando más yo/vamos cuando yo he trabaja(d)o más en eel- ¡uy! Perdón hee colabora(d)o o he esta(d)o así más en el barrio (...). (Preseval, [conv. 1, líneas 74-78]; http://www.uv.es/preseval/ppal.htm)

(6) Bueno, es decir, oye $<P A U S E>$ qué quieres, no sé. Dicen de que $<P A U S E>$ dicen Cruz y Raya de que yo hablo inseguro. Es que pienso que $<P A U S E>$ vamos, o sea, no estoy de acuerdo, pero $<$ PAUSE $>$ vamos, no sé, ¿no? O sea, yo creo $<P A U S E>$ yo que usted<PAUSE> vamos, no sé, ¿verdad, señor Gil?

(7) Pues venga, vamos, dale. (CREA; En una feria de barrio, Madrid, 08/08/91) 
(8) Yo también te buscaré algo, (...), solo falta que nos digas qué es... vamos, no te preocupes que seguro no le faltará nada. (http://www.foropadres.com/ viewtopic.php? $\mathrm{f}=90 \& \mathrm{t}=8102$ )

(9) A: ¿Te gusta (mostrando un vestido)?

B: ¡Vamos! Te va a quedar estupendo.

(10) www.elmundo.es/elmundo/2009/05/28/catalejo/1243510544.html por su_r00t el 28-05-2009 13: 51 UTC, publicado el 28-05-2009 15: 15 UTC

"Ha habido una tergiversación de los hechos teñidos de mentiras y falsedades", asegura un representante de la SGAE sobre el peculiar acceso -y registro según el afectado- a la casa de Juan José Coronel. La sociedad se remite al acta levantada por el juez que entró en la casa y asegura que "no se ha infringido la legalidad".

95 comentarios en: actualidad, sociedad karma: 774

etiquetas: sgae, juan josé coronel, registro, domicilio

negativos: usuarios: 464 anónimos: 604 compartir:

\#1 "No se ha infringido la legalidad".... anda, igual que con las descargas!!

votos: 86 , karma: 754

por perga el 28-05-2009 13: 53 UTC

\#12 Vamos no me jodas!!!! QUE LES DENUNCIE A LOS 5, (...).

por aitorbs el 28-05-2009 14:05 UTC

(http://meneame.net/story/sgae-ha-habido-tergiversacion-hechos)

Este marcador desarrolla funciones diversas relacionadas con la reformulación ${ }^{1}$ (13), la rearticulación ${ }^{2}(4-6)$ y la modalidad $^{3}(7-10)$. Las distintas lecturas que permiten los

\footnotetext{
${ }^{1}$ En este trabajo, aplicamos la etiqueta de reformulación a las operaciones de reformulación parafrástica que implican una relación variable de equivalencia conceptual entre el miembro reformulado y el miembro reformulador (Polanco, 2010). En cualquier caso, por reformular entendemos un volver a decir lo mismo de otra manera. Por ello, las operaciones discursivas que reflejan los ejemplos (4-6) no responden a lo que aquí entendemos por reformular, sino que implican un cambio en la dirección discursiva (4) o una operación continuativa no reformuladora (5-6).

${ }^{2}$ Tomamos el concepto de "rearticulación" de Luis Cortés y Ma Matilde Camacho (2005: 211-217). La rearticulación comprende funciones relacionadas con la reorganización y reparación discursivas de vamos (Polanco, 2010).

${ }^{3}$ En este trabajo, entendemos la modalidad como una función pragmática en sentido amplio, como concepto que engloba distintas funciones que sirven para expresar la actitud del hablante hacia la situación comunicativa, el interlocutor o el mensaje (propio y ajeno, explícito o implícito). Esta categoría agrupa valores pragmáticos como el acuerdo y el desacuerdo, el refuerzo, la matización, la faticidad y la expresividad. En algunos casos, estas funciones pragmáticas se asocian con valores convencionalizados, de modo que caen dentro de alguna de las categorías semánticas de la modalidad. En nues-
} 
ejemplos anteriores podrían achacarse a un caso de vaguedad semántica, esto es, a un enriquecimiento pragmático a partir de la interrelación del significado-función principal de vamos con el contexto. Y, de hecho, como expondremos en el apartado siguiente, esta es la consideración semántico-funcional que ha recibido generalmente este marcador. Sin embargo, si bien el recurso a un significado invariante permite explicar bien las funciones equifuncionales - por ejemplo, las funciones discursivo-textuales de reformulación y rearticulación (ejemplos 1-7) -, no parece tan evidente que esta perspectiva se aplique adecuadamente a todos los usos sincrónicos de este elemento discursivo.

En nuestra opinión, la polifuncionalidad de vamos no se reduce a la mera variación contextual a partir de una función predominante (o, lo que es igual, un único significado invariante). Más bien revela que este elemento discursivo es polisémico y presenta (i) más de un significado convencional asociado a determinadas funciones discursivointeractivas con rasgos gramaticales y semántico-pragmáticos estables diferenciados y (ii) varios sentidos contextuales con distinto grado de prominencia derivados de la interacción de los significados codificados con determinados contextos. Por ello, en este trabajo proponemos un modelo polisémico radial (Lakoff, 1987; Hansen, 2005; Evans, 2004, 2006) para el tratamiento semántico-funcional de esta unidad discursiva. Creemos que un modelo polisémico de este tipo permite describir y explicar adecuadamente (i) la variabilidad categorial, semántica y funcional de unidades discursivas complejas como vamos; (ii) los vínculos que existen entre los distintos usos de estas unidades; $y$, en definitiva, (iii) la estructura gramático-funcional subyacente de estos elementos.

En los siguientes apartados, exponemos las limitaciones que plantea un enfoque homonímico o monosémico para el tratamiento semántico de vamos (2.1. y 2.2., respectivamente), así como las ventajas que aporta una consideración polisémica de este elemento discursivo (2.3.). En el aparado 3, abordaremos la configuración del modelo polisémico que proponemos en este trabajo. Y, por último, en el apartado 4 se determinarán los sentidos codificados que conforman la red semántica de vamos.

\section{Variación funcional y representación semántica: ¿polifuncionalidad y/o polisemia?}

La variación semántica de los marcadores discursivos puede tratarse, fundamentalmente, desde tres enfoques metodológicos (Hansen, 1998a: 85 y ss.; 1998b): (i) una postura maximalista u homonímica, (ii) una postura minimalista o monosémica o (iii)

tro caso, como veremos en el apartado 4, las funciones conativa y fática de vamos convencionalizan valores semánticos relacionados con la modalidad deóntica. 
una postura polisémica. La visión homonímica trata la variación interpretativa como parte del contenido semántico de las palabras y representa esta variación mediante distintos sentidos no relacionados en el lexicón (una forma, más de un significado). En cambio, la perspectiva monosémica concibe el significado de una palabra como una constante de naturaleza abstracta (subespecificada) que cobra vida en el uso y que deriva distintas interpretaciones en función del contexto y de la situación comunicativa (una forma, un significado). La perspectiva polisémica, por el contrario, asume que el componente semántico de un elemento lingüístico puede estar constituido por varios sentidos convencionales relacionados, bien por medio de un componente semántico común (Wierzbicka, 1996; Travis, 2005), bien mediante una relación de encadenamiento a partir de relaciones de semejanza de familia o a través de la extensión desde un prototipo (Lakoff, 1987; Hansen, 1998b, 2005; Croft y Cruse, 2004; Evans, 2004, 2005).

\subsection{Homonimia}

La definición tradicional de homonimia establece que una misma forma léxica comparte más de un significado no relacionado (al menos, en el nivel sincrónico), en oposición al criterio clásico de polisemia, según el cual una forma léxica posee dos o más significados relacionados (Lyons, 1977: 550). No obstante, la línea que separa la homonimia de la polisemia es, a veces, poco nítida, y depende teóricamente de la aplicación de una perspectiva de análisis sincrónica o diacrónica (Croft y Cruse, 2004: 111). Así ocurre, por ejemplo, con las palabras banco o gato, que codifican significados como entidad financiera y asiento, y animal y herramienta, respectivamente. Estos significados pueden entenderse como significados independientes no relacionados entre sí, asociados a dos entradas en el lexicón, en cuyo caso se conciben como formas homónimas. No obstante, también podría hablarse de polisemia si se propone que existe una vinculación semántica entre ambos significados, ya sea mediante un componente semántico común ${ }^{4}$ (perspectiva sincrónica), ya sea por medio de una vinculación metafóricometonímica (perspectiva diacrónica).

\footnotetext{
${ }^{4}$ Dentro del marco teórico del Metalenguaje Semántico Natural, por ejemplo, la diferencia entre homonimia y polisemia se fundamenta en la noción de significado invariante compartido. En este sentido, las definiciones de un elemento polisémico deben compartir un núcleo semántico (una invariante semántica) o una invariante semántica parcial, parcial en tanto que esta invariante no da cuenta por sí misma de todo el significado, pero invariante porque está presente en todos los usos del lexema (Wierzbicka, 1988, 1996; Travis, 2005). Por tanto, allí donde no haya una invariante semántica parcial habrá homonimia.
} 
Asimismo, según el criterio clásico, la relación semántica entre formas léxicas homógrafas o derivadas pertenecientes a clases gramaticales distintas debería imputarse a un caso de homonimia. Desde este punto de vista, vamos podría considerarse un ejemplo de homonimia, ya que presenta, como se verá en el apartado 4 , un comportamiento gramatical divergente que permite su clasificación en tres posibles categorías: verbo, interjección y conector parentético ${ }^{5}$. Sin embargo, esta consideración semántica desestima el hecho de que la relación entre sentidos puede extenderse más allá de los límites categoriales entre lexemas, como parecen demostrar algunos estudios dentro del marco teórico de la semántica cognitiva (Brugman, 1988) o que aplican esta perspectiva teórica al estudio de los marcadores discursivos (Hansen, 1998b, 2005; Waltereit, 2006). En este sentido, siempre que pueda establecerse un punto de contacto entre los distintos significados que expresa una forma lingüística, aunque estos significados se asocien a categorías gramaticales diferentes de una misma forma (como en el caso de formas como bueno, vamos o vaya, por ejemplo), creemos que es preferible desestimar la opción de la homonimia y establecer una explicación más coherente con la estructura semántica subyacente. Al cabo, los hablantes pueden percibir que los diferentes usos de una palabra están relacionados de alguna manera, aunque no sean capaces de establecer cuál es el vínculo exacto que los une (es decir, aunque las relaciones semánticas entre las distintas lecturas no sean apriorísticamente transparentes).

El enfoque homonímico, en nuestra opinión, no tiene en cuenta la relación semántica que existe frecuentemente entre los distintos sentidos homónimos, tal como demuestran algunos estudios diacrónicos sobre marcadores discursivos (Brinton, 1996; Traugott, 1997; Traugott y Dasher, 2002; Waltereit, 2006). Obvia, igualmente, que la relación entre los sentidos de una forma léxica, sujeta generalmente a un proceso de evolución y reinterpretación, o fruto de este proceso, puede establecerse a partir de parecidos de familia (Hansen, 1998b, 2005, 2006). Por ello, no parece una opción semántica adecuada para explicar los distintos sentidos de unidades complejas como vamos.

\footnotetext{
5 Tomamos la etiqueta categorial de conector parentético de Cuenca $(2001,2002)$. Según esta autora, buena parte de los denominados conectores discursivos (Pons, 1998; Montolío, 2001) presenta un comportamiento sintáctico-funcional bastante homogéneo a pesar de su diversidad formal, lo cual permite proponer una caracterización de estos elementos como clase de palabras diferenciada. En este sentido, el vamos reformulador y rearticulador presenta características gramaticales y funcionales comunes con los conectores parentéticos de Cuenca.
} 


\subsection{Monosemia}

Desde una perspectiva monosémica, como se ha apuntado antes, se atribuye una relación de uno a uno entre la forma lingüística y el significado asociado a esta (en el caso de los marcadores discursivos, generalmente entre su función principal y un sentido vinculado con ella). Un marcador, por tanto, codifica un significado invariante abstracto, del que los sentidos derivados son interpretaciones enriquecidas contextualmente. La vaguedad semántico-funcional (la polisemia funcional) se resuelve, pues, pragmáticamente.

En el caso de vamos, son varios los autores que han atribuido a este marcador una función primaria relacionada con la (re)formulación y/o con la modalidad enunciativa, funciones que se asocian con el significado del marcador. Así, por ejemplo, en relación con la función reformuladora, Briz $(1993,1998)$ incluye a vamos entre los marcadores metadiscursivos reformuladores, como atenuador explicativo que introduce un segmento discursivo que "precisa lo anterior, que reformula o concluye un proceso de argumentación precedente" (1998: 223, nota 35) 6 . Asimismo, Portolés (2001: 143) atribuye a vamos un valor reformulador recapitulativo que introduce una conclusión o recapitulación a partir de un segmento anterior. Por último, Cortés y Camacho (2005: 219) asignan a vamos una función primaria reformulativa como marcador textual de progresión temática que contribuye al desarrollo del tópico discursivo, encadenando las diferentes unidades discursivas que conforman el texto (actúa, pues, como un marcador conectivo cohesionador [2005: 192]).

En cuanto a la función modal de vamos, Fuentes (1998: 178) define el valor principal de este marcador como Es lo que yo quiero decir, valor que aúna su función reformuladora con la subjetividad enunciativa del hablante 7 . Por su parte, Martín Zorraquino (1999: 4177-4180) clasifica a vamos entre los marcadores enfocadores de la alteridad al considerar que su función primaria es reforzar la imagen positiva del hablante, ya que favorece "la comunión, con su propio discurso, de los participantes en la conversación,

\footnotetext{
${ }^{6} \mathrm{Al}$ actuar como atenuador, cabría pensar que vamos asume un valor modal primario que comparece con el valor metadiscursivo reformulador, en la línea de Fuentes (1998), aunque no queda especificado por el autor.

${ }^{7}$ Fuentes asigna a vamos un valor modal de énfasis en la subjetividad, es decir, de refuerzo del acto de habla, que coactúa con la función reformuladora. Para esta autora, la perspectiva discursiva del hablante se intensifica mediante el uso del marcador, que comunica tanto la intención de volver a decir de otra forma o de focalizar ciertos argumentos (función metadiscursiva) como la actitud del hablante respecto de su propia enunciación (función modal).
} 
al incluirlos en la misma esfera enunciativa, a través de la primera persona verbal que la partícula contiene" (1999: 4178). Finalmente, Chodorowska-Pilch (1999) otorga a este valor de cortesía de vamos la misma relevancia funcional, considerándolo el valor definitorio de este elemento ${ }^{8}$.

Esta postura metodológica permite, en principio, abordar la variación y la representación semántico-funcional de forma aparentemente económica y no redundante. Con todo, en nuestra opinión, presenta ciertas desventajas para el tratamiento de muchos marcadores gramaticalizados o en vías de gramaticalización como el que nos ocupa porque:

(i) se desestima (o queda sin explicar) el proceso de expansión semántica que experimenta una misma forma, es decir, cómo se origina el significado instruccional del marcador;

(ii) no permite explicar la relación entre los usos discursivos (conectivos y no conectivos) y los no discursivos (valores oracionales e interjectivos, entre otros), teniendo en cuenta que la mayoría de los MD son fruto de un proceso de gramaticalización desde usos léxicos;

(iii) no se explica cómo se desarrollan las distintas lecturas de un marcador, es decir, qué factores intervienen en la derivación de las posibles interpretaciones de un marcador y por qué se derivan esas lecturas y no otras;

(iv) no da cuenta de los distintos grados de prominencia de los diferentes sentidos que puede activar una misma unidad lingüística en contexto, esto es, de los diferentes grados de prototipicidad semántica;

(v) no permite especificar semánticamente las diferencias entre los distintos marcadores de una misma (sub)clase funcional con idéntico cometido pragmático9.

Incluso asumiendo que fuera posible encontrar una invariante de significado para vamos que permitiera subsumir todos sus usos sincrónicos, como se propone para otras

\footnotetext{
${ }^{8}$ Esta autora afirma que el marcador vamos funciona principalmente como un marcador discursivo interpersonal y no como una estrategia para expresar una nueva formulación.

${ }^{9}$ Los marcadores discursivos, especialmente los marcadores gramaticalizados, son unidades polivalentes que pueden funcionar en distintos niveles del discurso. Sin embargo, cada marcador actúa en el contexto conversacional con un valor determinado (principal o más saliente), que viene dado por su "naturaleza léxica, su emplazamiento sintagmático y, en correlación con éste, su naturaleza, su entorno prosódico” (Briz, 1998: 221).
} 
unidades lingüísticas polifuncionales desde otros modelos teóricos ${ }^{10}$, quedaría abierta la cuestión del alcance de ese significado básico y de la plausibilidad y rentabilidad psicolingüísticas de una generalización semántica de ese tipo. Por un lado, cabe preguntarse si dicho significado básico engloba todos los posibles y heterogéneos usos de esta forma lingüística, o solo los distintos usos equifuncionales (a saber, el verbal, el interjectivo y el discursivo). Y, por otro lado, plantea la cuestión de si los usuarios de una lengua generalizan realmente al máximo en la interpretación de unidades discursivas de este tipo (es decir, si deducen los sentidos puntuales a partir de un significado sumamente esquemático en función del contexto) ${ }^{11}$. $\mathrm{O}$ si algunas de estas interpretaciones con una frecuencia elevada presentan un grado de autonomía y de saliencia suficientes que permite considerarlas como significados independientes y fácilmente accesibles en la memoria discursiva del hablante, posibilidad interpretativa esta que reduciría considerablemente el coste cognitivo en la interpretación.

En cualquier caso, la posibilidad de encontrar invariantes semánticas, cuando esto es posible, no representa, en nuestra opinión, un argumento decisivo contra la representación polisémica de la variación funcional, dado que no impide: (i) reconocer la posibilidad, en el plano sincrónico, de establecer más de un significado básico a partir del que

\footnotetext{
${ }^{10}$ Algunas propuestas teóricas abordan la relación entre los distintos sentidos de un marcador como resultado de la interacción de un significado invariante con determinados factores contextuales que seleccionan el respectivo significado contextual. De esta manera se intenta dar cuenta de los mecanismos que intervienen en la desambiguación semántica de estos elementos. Estos mecanismos restrictores pueden consistir en principios generales de interpretación, como el Principio de Relevancia (Blakemore, 1987, 2002; Montolío, 1998, 2001; Portolés, 1998, 2001; Archakis, 2001; Murillo, 2000, 2003); en un sistema de parámetros pragmáticos que selecciona el respectivo significado contextual (Sweetser 1990; Redeker, 1991, 2006); en la referencia a un dominio comunicativo, entendido este como dominio cognitivo (Fischer, 2000a, 2000b, 2006a, 2006b, 2010) o función pragmática (Pons, 1998a, 2006) al que atienden los hablantes en función de la situación comunicativa y de la relación entre los interlocutores (por ejemplo, la gestión del habla, la retroalimentación comunicativa o la gestión de los turnos de habla); o en un contexto estructural y semántico particular que determina la lectura puntual del marcador (Nemo, 2002, 2006). Con todo, pese a que con estos enfoques metodológicos se establecen mecanismos estructurales, pragmáticos y cognitivos que permiten restringir las distintas interpretaciones contextuales de un marcador, sigue sin resolverse en qué medida dichas interpretaciones son meramente contextuales (pese a que, en muchos casos, esta parece una opción contraintuitiva) o presentan grados distintos de autonomía que permiten distinciones semánticas pertinentes y motivadas.

${ }^{11}$ Esta objeción apunta a lo que Croft (1998: 156 y ss.) denomina falacia de la generalidad (the generallity fallacy), que consiste en identificar la capacidad del lingüista para establecer una invariante semántica con la manera como los hablantes interpretan el significado en contexto. En principio, que un analista pueda aislar un componente de significado presumiblemente común a todos los usos de una forma lingüística no implica que los hablantes actúen del mismo modo.
} 
se derivan determinados sentidos contextuales; (ii) asumir, desde una perspectiva diacrónica, que los sentidos sincrónicos derivan de algún sentido anterior, que puede seguir activo o no en la actualidad y que no tiene por qué ser el sentido más representativo para el hablante, ni necesariamente el sentido básico; y (iii) concebir la organización del conocimiento que tiene el hablante de estas unidades como una red compleja de sentidos relacionados entre sí, esto es, como un complejo semántico estructurado.

\subsection{El modelo polisémico cognitivo}

Como hemos apuntado anteriormente, la polifuncionalidad de marcadores complejos como vamos no se reduce a la mera variación contextual a partir de un único significado invariante, sino que revela la naturaleza heterosémica ${ }^{12}$ de este elemento discursivo, esto es, su carácter polisémico y policategorial.

Visto desde la perspectiva de la Semántica Cognitiva, la polisemia no exige que los diferentes sentidos relacionados compartan un significado nuclear en todas sus posibles acepciones; esto puede ser más o menos evidente en algunos casos, pero no es imprescindible. Los distintos sentidos de una misma forma léxica pueden estar estructurados en forma de red, mediante una relación de semejanza de familia, de modo que un sentido puede estar relacionado solo con otro de los sentidos de la estructura y no con todos ellos (Lakoff, 1987; Taylor, 1995; Evans, 2005). Lo que mantiene la estructura es el encadenamiento de sentidos que conforman la estructura conceptual radial, no un núcleo semántico compartido que vertebra toda la estructura.

En nuestra opinión, con un modelo polisémico de tipo radial se pueden modelar adecuadamente las relaciones de solidaridad formal y semántico-pragmáticas que existen entre los distintos valores funcionales de unidades lingüísticas complejas como vamos. Un modelo de este tipo permite:

(i) dar cuenta del carácter evolutivo gradual de la mayoría de los MD: ciertos sentidos surgen a partir de sentidos ya existentes, lo cual condiciona el contenido semántico de los nuevos valores y establece determinadas pautas para la ampliación funcional;

\footnotetext{
${ }^{12}$ Tomamos el concepto de heterosemia de Frantisek Lichtenberk, quien utiliza este término para referirse a casos en los que dos o más significados o funciones "that are historically related, in the sense of deriving from the same ultimate source, are borne by reflexes of the common source element that belong in different morphosyntactic categories" (1991: 475).
} 
(ii) representar de manera coherente la relación semántica motivada que existe entre las distintas funciones que desarrolla una misma forma intercategorialmente (en el caso de vamos, por ejemplo, las funciones verbal, interjectiva y discursiva) e intracategorialmente (en el caso de vamos, como MD, funciones relacionadas con la (re)formulación, la estructuración conversacional y el refuerzo argumentativo; como interjección, funciones relacionadas con la relación interpersonal, la modalidad, etc.);

(iii) relacionado con el punto (i), representar la variación semántica de estos elementos como una estructura compleja con distintos grados de prototipicidad.

Al introducir el punto de vista evolutivo a la descripción sincrónica, puede explicarse de forma coherente la emergencia motivada de nuevos valores a partir de los ya existentes, esto es, el surgimiento de nuevos significados como extensiones metafóricas y/o metonímicas graduales de significados anteriores (Hansen, 2006; Waltereit, 2006). Como muestra la figura 1 , los nuevos significados convencionalizados pueden convertirse, a su vez, en generadores de implicaturas que se reinterpretan contextualmente, se generalizan y acaban afianzándose, produciendo así un nuevo ciclo de extensiones semánticas.

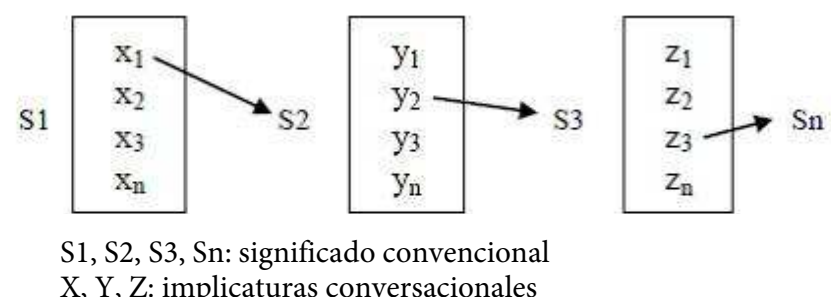

Figura 1. Ciclo de extensión semántico-funcional

La ampliación y especialización funcional conlleva cambios en las propiedades formales (por ejemplo, la pérdida de independencia estructural y comunicativa) y semántico-pragmáticas que dan lugar a traspasos categoriales, y favorece la creación de nuevos nódulos o espacios categoriales en la red compleja que conforma toda unidad lingüística (del rango que sea). En este sentido, un enfoque polisémico permite tratar casos como el de vamos como categorías complejas (o radiales [Lakoff, 1987]) con una estructura interna compuesta de diversos sentidos, entendidos estos como estructuras con unas determinadas características formales, semánticas y pragmáticas. 
El uso e interpretación de vamos, como el de las estructuras lingüísticas en general, tiene mucho que ver con el conocimiento metalingüístico y metapragmático ${ }^{13}$ que poseen de ellas los hablantes (lo que en este trabajo denominamos marco de interpretación). Buena parte de este conocimiento es convencional (o posee un grado elevado de convencionalidad), esto es, forma parte de lo que un hablante sabe acerca del uso e interpretación de ciertas estructuras. Con todo, asumir que los distintos sentidos que puede desplegar un marcador complejo mantienen relaciones de parentesco entre sí no significa que todas las interpretaciones posibles en contexto deban atribuirse a significados codificados.

De hecho, una de las objeciones que suele hacerse al modelo de red polisémica es, precisamente, la descripción altamente granular del significado o análisis de especificación completa que se propone en algunos trabajos ${ }^{14}$. Una descripción semántica de este tipo es cuestionable porque no permite distinguir entre la información codificada por una expresión léxica y la información derivable del co(n)texto y la situación comunicativa ${ }^{15} ; y$, no menos importante, porque un análisis granular tan amplio no ofrece suficientes garantías de plausibilidad psicolingüística. Por ello, para evitar la falacia de la polisemia $^{16}$ (Sandra, 1998), es necesario aplicar criterios de análisis más restrictivos.

Una objeción similar puede hacerse a algunos estudios sobre marcadores discursivos realizados desde un enfoque polisémico cognitivo, como el propuesto por Hansen (2005) para el marcador francés enfin ${ }^{17}$. La autora analiza un total de 14 usos diferentes del marcador para los que propone una reducción de sentidos a tres centrales o prototípicos y once derivados o periféricos. Sin embargo, el problema de la arbitrariedad per-

\footnotetext{
${ }^{13}$ Sobre el concepto de conciencia metapragmática, véanse Verschueren $(2000,2002)$ y Portolés (2004). ${ }^{14}$ Los trabajos de Brugman (1988), Lakoff (1987) y Brugman y Lakoff (1988) son ejemplos paradigmáticos de este tipo de análisis semántico. Así, por ejemplo, en el estudio de Brugman y Lakoff (1988) sobre las preposiciones inglesas, llega a proponerse para la preposición over una red semántica compuesta por 24 sentidos distintos.

${ }^{15}$ Para algunas críticas a este tipo de análisis semántico, véanse, entre otros, Sandra (1998), Sandra y Rice (1995), Evans (2000), Boogart (2009).

${ }^{16}$ Una sobreespecificación semántica de este tipo, tan poco restrictiva, induce a pensar que la posibilidad de poder establecer un número relativamente alto de sentidos diferentes relacionados para un elemento léxico implica que el usuario de la lengua debe de representar el significado (o significados) de las palabras de esta forma. Sin embargo, como arguye Sandra (1998), este razonamiento puede considerarse falaz, ya que no necesariamente todo posible sentido de una palabra en contexto responde a un componente de significado independiente, incluso desde un acercamiento intuitivo al significado léxico.

${ }^{17}$ En este estudio, Hansen propone una red semántica de tipo radial de orientación evolutiva, inspirada en el modelo de prototipos de Geeraerts (1994).
} 
siste, ya que en la distribución entre sentidos centrales y periféricos no se aplica ningún criterio fundamentado que explique la distribución propuesta. No obstante, pese a que esta propuesta polisémica parece una mejor opción descriptiva para los marcadores discursivos que otras aproximaciones de corte monosémico y una alternativa metodológica mejor fundamentada que la propuesta polisémica de especificación completa que hemos comentado arriba, el trabajo de Hansen no deja de ser una aproximación intuitiva que no acaba de justificar la diferenciación entre los sentidos prototípicos como sentidos independientes (relacionados evolutivamente dentro de la red semántica) y los sentidos satélite (derivados contextualmente de los anteriores y, por tanto, no almacenados en el lexicón como sentidos independientes).

Sin obviar la subjetividad potencial a la que está expuesto cualquier análisis lingüístico (en definitiva, el analista es también un usuario más de alguna lengua), es necesario sustentar metodológicamente la descripción semántica de un elemento lingüístico con pautas de análisis falsables ${ }^{18}$. En este sentido, tal como propone Evans (2001: 727), es preciso desarrollar criterios que permitan, por un lado, distinguir los diferentes sentidos que conforman la red semántica de un elemento léxico; y por otro, determinar el o los sentidos centrales o primarios de ese elemento léxico. Por ello, para el establecimiento de la red semántica de vamos proponemos una adaptación del modelo polisémico propuesto por Andrea Tyler y Vyvyan Evans (2001, 2003), posteriormente implementado por Evans (2004), a saber, el Modelo de polisemia fundamentada (principled polyse$m y)$.

\section{El modelo de polisemia fundamentada ${ }^{19}$}

El Modelo de polisemia fundamentada (de ahora en adelante, MPF) ha sido desarrollado, principalmente, para el análisis semántico de categorías léxicas conceptuales. No

\footnotetext{
${ }^{18}$ Sandra y Rice (1995) arguyen que cualesquiera de los análisis de la estructura de red polisémica realizados hasta el momento, incluyendo el análisis del que pudiera constituir el sentido primario de la red semántica, es relativamente arbitrario, puesto que refleja las preferencias personales (cuando no la propia imaginación) del analista. Esta crítica se fundamenta en la ausencia de criterios delimitados y falsables que parece caracterizar los estudios cognitivos sobre la polisemia de algunas preposiciones inglesas, como el enfoque de especificación completa (full-specification approach) que aplica Lakoff (1987) al estudio de la preposición over, del que Sandra sostiene que "what is lacking from the exercise is a set of scientifically valid principles" (Sandra, 1998: 371).

${ }^{19}$ Para el desarrollo original de este modelo polisémico, véanse principalmente Tyler y Evans, 2001, 2003; Evans y Tyler, 2004a, 2004b; y Evans, 2004, 2005.
} 
obstante, creemos que es posible su implementación teórica en categorías gramáticofuncionales, como trataremos de demostrar con el análisis semántico de vamos.

Partiendo de la propuesta de Evans (2004, 2006), los principios fundamentales del MPF pueden resumirse en los siguientes puntos:

(i) Un lexema puede presentar, en el nivel sincrónico, cierto número de sentidos distintos almacenados de modo independiente en la memoria semántica, que se derivan históricamente de un primer sentido original.

(ii) En el nivel sincrónico, los distintos sentidos pueden analizarse como elementos relacionados dentro de una red semántica. Estos se organizan a partir un sentido básico o sancionador (sanctioning sense, Langacker [1987: 157]) que presenta típicamente (aunque no forzosamente) similitudes con el sentido diacrónicamente más temprano. El sentido sancionador se toma como sentido prototípico, ya que constituye el sentido de citación al que los hablantes recurrirán con más probabilidad en respuesta a la pregunta "¿qué significa la palabra X?"20. Con todo, como apunta Hansen (2005), hay que prever la posibilidad de que haya más de un significado básico (o sancionador) que sea igualmente prominente para los hablantes. De hecho, como se verá más adelante, esto es lo que parece ocurrir en el caso de vamos.

(iii) Los distintos sentidos de una forma léxica son, en definitiva, el resultado de un proceso dinámico de extensión semántica, pese a que es posible que los usuarios de una lengua no reconozcan con nitidez una relación sincrónica entre todos ellos. De hecho, modelar las relaciones entre sentidos en términos de una estructura radial permite identificar diferentes grados de parentesco, con miembros periféricos menos relacionados con el sentido sancionador que los miembros más centrales (Lakoff, 1987; Langacker, 1987; Tyler y Evans, 2003; Evans, 2004).

\footnotetext{
${ }^{20}$ No obstante, de aquí no se sigue que el sentido sancionador deba coincidir con el sentido más frecuente, tal como se desprende del uso de muchas palabras polisémicas cuyo(s) sentido(s) prototípi$\operatorname{co}(\mathrm{s})$ no coincide(n) con el sentido más utilizado estadísticamente, sino con el más relevante desde el punto de vista cognitivo; esto es, con el sentido más prominente y fácilmente reconocible. Piénsese, por ejemplo, en la expresión 'coño', cuyo sentido más prominente sea seguramente la manera vulgar de nombrar el órgano sexual femenino, aunque estadísticamente quizá sean más frecuentes los usos interjectivos relacionados con la expresión de sorpresa, rechazo, enfado, etc.
} 


\subsection{La configuración del modelo polisémico}

Para la configuración del modelo polisémico, partimos de la idea de que vamos constituye una unidad lingüística, esto es, un emparejamiento convencional de forma y sentido (Lakoff, 1987; Taylor, 2003; Tyler y Evans, 2003; Sandra y Rice, 1995).

El polo semántico de este emparejamiento se estructura en forma de una red semántica organizada en torno a un sentido básico o sancionador (o más de uno, si fuera el caso, tal como se ha apuntado antes) ${ }^{21}$, que no tiene por qué coincidir, en principio, con el sentido diacrónicamente más antiguo o sentido original (origination sense, Evans y Tyler [2004b]). No obstante, puesto que el primer significado más antiguo (diacrónicamente) puede continuar todavía activo en la red semántica sincrónica, el sentido original y el sentido básico (o uno de ellos) pueden solaparse, como ocurre en el caso de vamos (ver \$3.1.2.4). La propuesta de un sentido básico o sancionador se basa en el hecho de que los hablantes parecen categorizar intuitivamente los sentidos a partir de un prototipo léxico (Lakoff, 1987; Taylor, 2003; Evans y Green, 2005). La red semántica de una palabra puede organizarse a partir del sentido sancionador en forma de estructura radial, lo cual favorece la comprensión de grados de parentesco entre los distintos sentidos y permite dar cuenta de la apariencia de encadenamiento dentro de las categorías (Lakoff, 1987).

\footnotetext{
${ }^{21}$ Una forma léxica particular no tiene por qué partir necesariamente de un solo sentido sancionador a partir del cual los usuarios de la lengua categoricen todos los demás sentidos asociados con un elemento léxico (Sandra y Rice, 1995). En este sentido, la polisemia no se define necesariamente como un fenómeno estrictamente sincrónico en el que se mantiene una relación entre los distintos sentidos de una forma léxica dada, de la que los hablantes son plenamente conscientes. Sin embargo, esta es una cuestión para la que no parece haber aún suficiente evidencia empírica. Si, como arguyen Evans y Tyler (2004b), la evidencia experimental demostrara que los hablantes fallan sistemática y consistentemente a la hora de percibir la relación entre algunos sentidos, podría ponerse en tela de juicio la consideración de que el fenómeno de la polisemia constituye un fenómeno de naturaleza completamente sincrónica.

Por tanto, mientras sea plausible mantener que todos los sentidos de una determinada red semántica están relacionados diacrónicamente, en el lexicón habrá diferencias en el parentesco percibido entre distintos sentidos, debido a la rutinización y el afianzamiento (pragmatic strengthening), fenómenos que desdibujarían la motivación original para derivar sentidos nuevos desde otros preexistentes, como el sentido primario. Los diferentes procesos de cambio lingüístico provocan que no todos los sentidos asociados con una forma determinada puedan reconocerse como sincrónicamente relacionados. Es decir, aunque la extensión semántica esté muy motivada, puede dar lugar a una red semántica que el hablante (e, incluso, el analista) conciba como solo parcialmente motivada (Evans y Tyler, 2004b: 165 nota 9$)$.
} 
Asimismo, en relación con el análisis semántico que presentamos en este trabajo, es necesario hacer dos distinciones relevantes: por un lado, entre sentido central (o sentidos centrales, como veremos después) y sentido periférico (Hansen, 2005); por otro lado, entre sentido y elaboración de un sentido particular.

En el primer caso, entendemos por sentido central un sentido de la red semántica a partir del cual se organizan otros sentidos con distintos grados de afinidad semántica respecto de aquel. Estos sentidos más periféricos pueden ser extensiones semánticas del sentido central o extensiones de sentidos derivados del sentido central, de modo que los sentidos periféricos presentan distintos grados de prototipicidad, esto es, de alejamiento del centro categorial.

En cuanto a la segunda dicotomía, sentido frente a elaboración, un sentido constituye un significado distinto e identificable, mientras que una elaboración pertenece a la naturaleza del contenido semántico de un sentido afianzado particular (Evans, 2005). Es decir, tal como lo entendemos en este trabajo, una elaboración es el desarrollo contextual de un sentido afianzado.

\subsubsection{Determinación de los sentidos de la red semántica}

En este apartado, establecemos los criterios que se tendrán en cuenta para distinguir los significados codificados de los significados co(n)textuales y efectos de sentido derivados. Siguiendo a Evans $(2004,2005)$, se proponen tres criterios de análisis:

a) Criterio semántico (meaning criterion). Un sentido será diferente de otro si aporta un significado adicional que no esté ya presente en ningún otro sentido asociado con la estructura analizada. Este criterio se fundamenta en el supuesto de que un sentido será diferente de otro si presenta un significado distinto.

b) Criterio de elaboración semántica ${ }^{22}$ (concept elaboration criterion). Un nuevo sentido presentará patrones o esquemas de elaboración semántica únicos o claramente distintos; es decir, presentará distintas tendencias de selección semántica. Este criterio alude a los elementos léxicos que coaparecen en relación sintagmática o colocacional con el lexema analizado y atañe, por tanto, a la modificación cotextual de un sentido básico. En el caso que nos ocupa, también pueden establecerse tendencias de selección semántica, teniendo en cuenta que

\footnotetext{
${ }^{22}$ Utilizamos el término semántico en lugar de conceptual dadas las características semánticas del tipo de unidades lingüísticas que estamos tratando: codifican instrucciones de procesamiento o significado procedimental, no conceptual.
} 
algunas de las instrucciones de vamos se asocian a relaciones sintagmáticas prototípicas entre este elemento y ciertos actos de habla.

c) Criterio gramatical (gramatical criterion). Un nuevo sentido manifestará dependencias estructurales únicas o claramente diferenciadas. Este criterio concierne, pues, a las tendencias de selección formal o gramatical que determinan en qué construcciones gramaticales puede aparecer un lexema. Para que un sentido sea distinto, debe mostrar un comportamiento gramatical distintivo.

De los tres criterios expuestos, el más importante es, en principio, el criterio semántico, puesto que es el que permite distinguir sentidos diferenciados. No obstante, debido a la innegable influencia que ejerce el co(n)texto a la hora de identificar el uso particular de un sentido determinado, sería preciso tener en cuenta al menos alguno de los otros dos criterios. La razón, en definitiva, es ajustar al máximo los juicios de distintividad semántica por parte del analista, para evitar una proliferación innecesaria de sentidos que, en muchos casos, son explicables como resultado de inferencias (con distinto grado de activación) a partir del uso de un sentido básico en un contexto determinado ${ }^{23}$.

Los criterios anteriores tomados en conjunto permiten perfilar mejor la atribución de significados codificados dentro de la red semántica asociada con el lexema analizado. Asimismo, este modelo aporta la ventaja de que los criterios expuestos "offer a rigorous and relatively consistent (i.e. inter-subjective) methodology for assessing what counts as a diferent sense" (Evans, 2004: 43). En este sentido, creemos que suponen una pauta metodológica firme en la que fundamentar el análisis polisémico de elementos discursivos complejos como el que nos ocupa ${ }^{24}$.

\footnotetext{
${ }^{23}$ Para una revisión crítica, desde una perspectiva cognitivista, sobre la necesidad de acotar el número de sentidos asociados con una forma léxica determinada, véase Sandra y Rice (1995) y Tyler y Evans (2001).

${ }^{24}$ No obstante, no puede obviarse que determinar qué significados constituyen en realidad sentidos distintos de una forma léxica continúa siendo una cuestión empírica abierta - esta reserva atañe también, sin duda, a la plausibilidad del establecimiento de un único sentido invariante o básico-. Por otra parte, también debe considerarse el hecho de que la interpretación de significados diferentes no tiene por qué seguir una única vía de afianzamiento y estructuración en la memoria semántica, idéntica para todos los hablantes de una misma comunidad. En el caso de vamos, por ejemplo, puede ocurrir que algunos hablantes deriven significados contextualmente mientras que otros ya hayan convencionalizado esos mismos componentes de significado (dependerá, en buena medida, de la experiencia discursiva previa con elementos de estas características, del conocimiento metalingüístico del hablante-oyente, de sus habilidades lingüístico-discursivas, etc.).
} 


\subsubsection{Determinación del sentido sancionador o central}

Para determinar el sentido sancionador de la red semántica de vamos, esto es, el sentido central sobre el que se organizan los demás sentidos, hemos tenido en cuenta los siguientes criterios: el sentido registrado más antiguo (\$3.1.2.1); el predominio de algún sentido en la red semántica (\$3.1.2.2); y la predictibilidad de expansión semántica $(\$ 3.1 \cdot 2 \cdot 3)^{25}$.

\subsubsection{El sentido registrado más antiguo}

Según este primer criterio, el sentido sancionador será aquel sentido sincrónico que mantenga una relación más estrecha con el sentido documentado más antiguo, puesto que este primer sentido posiblemente desempeñara un papel relevante en el desarrollo posterior de nuevos sentidos. De ahí que el primer sentido registrado diacrónicamente abogue por la centralidad dentro de la red semántica.

A partir de los datos diacrónicos de que disponemos ${ }^{26}$, el sentido de vamos más antiguo diacrónicamente que ha podido servir de motor originador de la posterior extensión semántico-funcional de este elemento es el propio de su uso como subjuntivo independiente: el de exhortación ${ }^{27}$. Tal como plantea el Esbozo de la RAE (1973: \$3.13.2a),

\footnotetext{
${ }^{25}$ Evans propone también un cuarto criterio, el de la experiencialidad, que no adoptaremos en nuestro análisis. En el caso del sustantivo time estudiado por Evans, la experiencia del tiempo en el nivel fenomenológico ayuda a determinar el sentido sancionador. La experiencia subjetiva del hablante sobre el tiempo implica la conciencia de la duración del tiempo, del tiempo como magnitud temporal. Esto da lugar, según Evans, a la habilidad del hablante para distinguir la actividad y el momento presentes de un momento ya pasado, y su habilidad para calibrar el transcurso de los eventos (Evans, 2004, 2005). Por tanto, el criterio de la experiencialidad establece que el componente semántico que mejor se ajuste con esta experiencia vivida del tiempo será, probablemente, el sentido sancionador de la red semántica (en el estudio citado, es el sentido de duración).

${ }^{26}$ Para vamos, véanse Gonzalez Ollé (2002) y Romero (2006).

${ }^{27}$ Como pone de manifiesto González Ollé (2002), la forma vamos que interesa en este trabajo procede de una $1^{\text {a }}$ persona del plural del presente de subjuntivo ( $<$ lat. vadimus) y no del presente de indicativo (Martín Zorraquino y Portolés, 1999: 4178), como cabría esperar por la identidad formal con esta forma verbal. Las formas vamos y vais se utilizaron, hasta el siglo XVI, como alomorfos del presente de subjuntivo vayamos y vayáis (< lat. vadamus y vadatis, respectivamente). El origen subjuntivo de vamos permite explicar, en nuestra opinión, la posterior evolución de la forma verbal hacia valores interjectivos, en los que pervive el valor modal deóntico de exhortación propio del subjuntivo independiente. De lo contrario, la evolución de vamos presentaría una trayectoria evolutiva divergente, y difícil de explicar, respecto de la de otras formas subjuntivas de verbos de movimiento, como vaya y venga, en las que el paso del significado de "movimiento" al de "modalidad deóntica" se justifica de
} 
el uso del subjuntivo en español ha ido ligado a la expresión modal de las actitudes del hablante hacia el evento descrito, bien para evaluarlo (duda, posibilidad, desconocimiento, etc.), bien para mostrar el compromiso del hablante con su realización efectiva (deseo, exhortación, mandato, etc.). Es precisamente el segundo grupo de valores, propios del subjuntivo en oraciones independientes, el que incide sobre la capacidad del hablante de instar a la realización del evento o de controlarlo (Toledo, 2001: 41). Como apunta Romero (2006: 54), los verbos de movimiento muestran "una gran flexibilidad para descategorizarse y recategorizarse" en interjecciones y marcadores discursivos a partir de las formas de subjuntivo (vamos, vaya y venga, por ejemplo) e imperativo (an$d a)$.

A medida que vaya desdibujándose el valor verbal de movimiento en vamos, irán perfilándose, mediante el refuerzo de implicaturas, los valores modales deónticos implícitos en esta forma subjuntiva, entre los que figuran el de exhortación (vamos conativo) y el de aceptación enfática (vamos fático). Junto con el refuerzo implicatural, los procesos de reconceptualización metafórica han incidido también en la extensión semánticofuncional de vamos, especialmente en el surgimiento del valor formulativo de este elemento. Al fin y al cabo, la consideración metafórica o metonímica del proceso depende de la perspectiva que se adopte. Así, si se focaliza el inicio y el final del proceso desde el vamos subjuntivo al vamos marcador discursivo, puede verse un cambio metafórico, de dominio (espacial > volitivo > discursivo). Si se realiza un análisis evolutivo, secuencial, cobra mayor peso el refuerzo de implicaturas, de sentidos secundarios que pasan a un primer plano en determinados contextos (contigüidad de significados, refuerzo pragmático, metonimia). Si se analizan sincrónicamente, los nuevos sentidos y funciones que se van afianzando no desplazan a los significados anteriores, sino que conviven, creando una red polisémica de sentidos relacionados entre sí.

El valor exhortativo del subjuntivo independiente que hemos comentado continúa vigente en el plano sincrónico de vamos en contextos en los que la forma verbal constituye un acto de habla directivo, como muestra los siguientes ejemplos:

(11) a. Vamos nosotros, que ellos ya vendrán

b. Vamos para allá cuanto antes, que llegaremos tarde

forma sencilla por el debilitamiento del primer valor y un refuerzo implicatural de los valores modales intrínsecos al subjuntivo, en contextos de uso independiente. De otra parte, como señala González Ollé (2002: 132), la función modal que atribuye Fuentes (1998) a vamos, en que la subjetividad y la enfatización del hablante son rasgos destacados, se corresponde mejor con el modo verbal subjuntivo que con el indicativo. 
Se produce, por tanto, un solapamiento entre el sentido original y uno de los sentidos actuales. Ahora bien, aunque el valor modal de exhortación es muy fuerte en el uso verbal, tanto que puede confundirse con el uso interjectivo en muchos casos, el comportamiento gramatical distinto que muestran ambos usos permite hablar de dos sentidos diferentes ${ }^{28}$. La forma verbal se interpreta en contextos en los que vamos: (i) indica la voluntad del hablante de realizar un movimiento real con una meta concreta; y (ii) no ha cancelado su sintaxis verbal (Company, 2004a, 2004b), esto es, su capacidad de regir argumentos: (a) puede explicitarse el sujeto que realiza el movimiento (sujeto prototípico), con el que concuerda (Vamos nosotros/tú, yo y Pepe, que ellos ya vendrán); (b) puede haber complementos locativos o temporales que dependen de la forma verbal ( $\mathrm{Va}$ mos para allá cuanto antes, que llegaremos tarde).

\subsubsection{El predominio en la red semántica}

En segundo lugar, además del valor registrado más antiguo, debe considerarse el predominio que pueda ejercer algún sentido dentro de la red semántica (frecuencia de tipo). Este predominio en la red semántica puede ayudar a precisar el sentido sancionador.

Según lo que hemos podido comprobar en el corpus analizado, el sentido predominante en la red semántica de vamos no es el que se corresponde con el uso verbal que hemos comentado en el apartado anterior, sino el interjectivo y, especialmente, el formulador. Teniendo en cuenta que el sentido central o básico se plantea como aquel que responde con mayor facilidad a la pregunta “¿qué significa X?”, y que el valor más frecuente no se corresponde siempre con el valor más representativo (es decir, con el valor más saliente, que se activa con mayor rapidez o facilidad fuera de contexto; ver nota 20), la frecuencia de uso constituye un criterio relativo para determinar el sentido sancionador de una red polisémica como la que planteamos, en la que se tiene en cuenta la evolución diacrónica de una forma lingüística.

\subsubsection{La predictibilidad de expansión semántica}

En tercer lugar, a partir de la idea defendida anteriormente de que la extensión semántica está fundamentada y motivada, y de que las extensiones semánticas se derivan del uso contextualizado (la lengua es un sistema fundamentado en el uso), el sentido

\footnotetext{
${ }^{28}$ Las características gramaticales de los usos interjectivos de vamos se tratarán en los apartados dedicados al análisis de los sentidos codificados ( $\$ 4.1 .1 .3$ y $\$ 4.1 .2 .3)$.
} 
sancionador será aquel del que puedan derivarse -o haberse derivado- con mayor naturalidad los demás sentidos de la red semántica. Como hemos visto antes, el valor del que se han derivado los demás sentidos de vamos es, sin duda, el valor verbal en su uso como subjuntivo libre.

\subsubsection{El sentido sancionador o central}

De la aplicación de los tres criterios aducidos anteriormente, dos de ellos, el del sentido más antiguo registrado y el de la predictibilidad de expansión semántica, apuntan claramente hacia el sentido verbal (valor exhorativo) como sentido sancionador de la red semántica de vamos. Sin embargo, pese a que este sentido ha sido el origen del cambio semántico-funcional posterior de estos elementos, parece quizás menos claro que deba constituirse en el centro categorial.

Si bien, desde una perspectiva evolutiva, el sentido sancionador original constituye el centro vertebrador de la red polisémica y puede seguir activo en el plano sincrónico, hay que prever la posibilidad de que otros sentidos evolucionados posteriormente hayan alcanzado un grado de autonomía semántico-funcional suficiente que los convierta en sentidos prominentes para los hablantes. Esto es, que sean percibidos sincrónicamente como sentidos básicos que, a su vez, se han convertido - o pueden hacerlo- en generadores de nuevos sentidos (en función del criterio de predictibilidad de expansión semántica que hemos comentado antes). Nada impide que un sentido evolucionado posteriormente constituya la lectura dominante en el plano sincrónico, dado el carácter flexible de las categorías prototípicas, cuyos núcleos cambian a lo largo del tiempo (Traugott y Dasher, 2002: 8).

Aunque no es infrecuente que coexistan ambos significados (el histórico y el central), como ocurre en el caso de vamos, creemos que es necesario realizar una distinción metodológica entre significados sancionadores originales en el plano diacrónico y significados sancionadores básicos sincrónicamente (Hansen, 2005: 41). De este modo, se capta adecuadamente la intuición de que los sentidos de una unidad lingüística están relacionados entre sí mediante vínculos de distinta naturaleza, conformando una estructura compleja pero cohesionada.

Igualmente, puede integrarse la tendencia monosémica hacia un sentido invariante o central como elemento vertebrador de la categoría, entendiendo el sentido invariante como uno de los sentidos prominentes de la red semántica a partir del que se interpre- 
tan contextualmente otros sentidos ${ }^{29}$. En el primer caso, en el que se percibe una relación estructurada entre los diferentes sentidos de una forma lingüística, se concibe la categoría en su conjunto, de forma holística, de modo que todos los significados conforman un todo, una unidad (figura 2A). En el segundo caso, en el que se focaliza un sentido de la estructura semántica, realizamos una parcelación de un todo inaprehensible a priori, pero intuible (figura $2 \mathrm{~B}$ ).

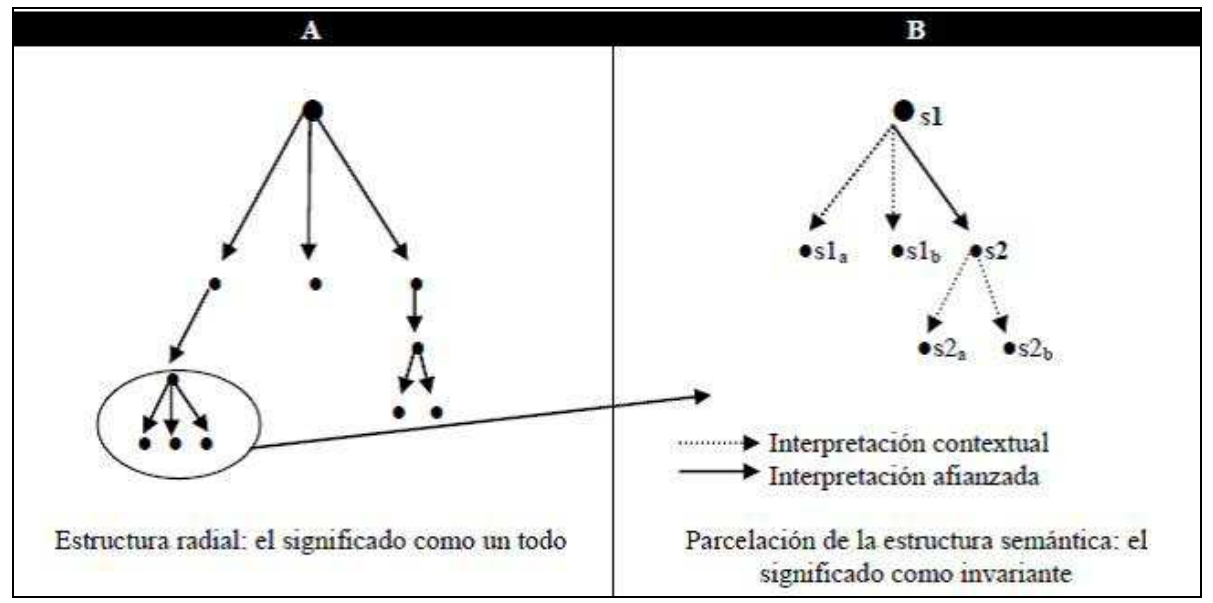

Figura 2. Estructura semántica radial y componentes de significado de un elemento lingüístico

Las interpretaciones puntuales parten de un significado más básico que se enriquece contextualmente; estos sentidos pueden unificarse en el sentido básico más abstracto, en tanto que parte constitutiva, o pueden afianzarse, asumiendo rasgos de comportamiento funcional divergentes respecto del sentido básico y no unificables con él, dando lugar a nuevos sentidos susceptibles, a su vez, de variación contextual. En este sentido, polisemia y monosemia pueden convivir dentro de la red semántica, ya que no todos los sentidos tienen que originar necesariamente nuevos sentidos independientes (aunque esta sea una tendencia natural ${ }^{30}$.

\footnotetext{
${ }^{29}$ Esta consideración permite salvar objeciones al modelo polisémico como la que plantea Boogart (2009: 220). Según este autor, el modelo polisémico, al desestimar la necesidad de establecer un significado invariante, no permite determinar cuál es el vínculo común entre los distintos usos de una forma lingüística.

${ }^{30}$ En cualquier caso, tal como lo entendemos en este trabajo, la diferencia entre polisemia (un signo, varios sentidos independientes relacionados) y monosemia (un signo, un significado independiente,
} 
En el caso de unidades lingüísticas polifuncionales y policategoriales como vamos, consideramos que la atribución de un único sentido sancionador o básico no parece una solución adecuada. Estos elementos presentan sentidos fuertemente afianzados, con características gramaticales y semántico-pragmáticas diferenciadas, que se muestran como candidatos legítimos a ocupar la posición de centro categorial. Asimismo, cada uno de estos sentidos constituye, a su vez, el motor generador de otros subsentidos que no dependen ya del sentido original sino de forma incidental. De este modo, la divergencia semántica apunta no ya hacia una consideración polisémica respecto de un significado central, que puede mantenerse para una descripción parcelada de la red semántica (como trata de representar la figura 2B), sino hacia un comportamiento multicategorial, esto es, heterosémico. De ahí que consideremos factible, y probablemente más adecuado a la realidad funcional de vamos, la atribución de más de un sentido central $^{31}$ dentro de la red semántica sincrónica de estos elementos, tal como tratamos de demostrar en el siguiente apartado.

\section{La red semántica de vamos}

Una vez establecidos los fundamentos teóricos del modelo polisémico que queremos aplicar a vamos y los criterios que sustentan la modelación de la red semántica de este elemento complejo, en este apartado se desarrollarán los sentidos codificados de dicha red semántica.

La forma vamos representa un recurso lingüístico que se usa de manera convencional en determinados contextos protototípicos para llevar a cabo funciones relacionadas con:

a) la (re)organización de la materia discursiva (reformulación y rearticulación; de manera genérica, marcar continuación discursiva);

varios sentidos contextuales) es una cuestión de grado evolutivo y de saliencia cognitiva. Los distintos sentidos que en un momento del proceso evolutivo de un signo (sincronía) pueden ser reducibles a una invariante (análisis monosémico), pueden derivar en sentidos independientes a medida que se afianzan las interpretaciones contextuales (refuerzo y convencionalización de implicaturas; diacronía); igualmente, los sentidos que un usuario de la lengua puede percibir como interpretaciones contextuales de un sentido más básico, otro puede percibirlos como sentidos independientes (con propiedades formales, distribucionales y semántico-pragmáticas distintas), claramente distinguibles.

${ }^{31}$ Como ya habíamos señalado anteriormente, es preferible distinguir entre la polisemia vinculada con un sentido de la red semántica (polisemia intracategorial) y la polisemia global de la estructura semántica de una unidad lingüística dada, que afecta a más de un sentido afianzado y, en consecuencia, a más de una categoría gramatical (polisemia intercategorial o heterosemia). 
b) la mostración del (des)acuerdo con un (inter)locutor presencial o virtual, mostrando la (dis)conformidad con un punto de vista, con una intención o con un determinado estado de cosas (función fática ${ }^{32}$; modalidad deóntica);

c) la voluntad del hablante de influir en la conducta de su interlocutor (función conativa; modalidad deóntica) ${ }^{33}$.

Las funciones mencionadas constituyen funciones genéricas de vamos ${ }^{34}$. Estas funciones, asimismo, se vinculan prototípicamente con determinados contextos funcionales que prevén, a su vez, la aparición de estos elementos discursivos como elementos prototípicos para vehicular dichas funciones (Polanco, 2010). En este sentido, puede decirse que estas funciones básicas constituyen también sentidos afianzados dentro de la red polisémica de este elemento discursivo, a saber: el sentido conativo (4.1.1), el sentido fático (4.1.2) y el sentido formulativo (4.1.3).

\subsection{Los sentidos codificados}

\subsubsection{Vamos conativo: la exhortación}

Los ejemplos (9) y (10) del apartado 1, que repetimos a continuación, ilustran el sentido conativo de vamos:

(9bis) < PER001"> <OVERLAP><VOCAL "INTERROGACIÓN" "¿EH?"></OVERLAP> bien, entonces ya vamos a darnos un poco de prisa, que si no no va a darnos tiempo a todos, y además hacer algunos comentarios que tengo que hacer.

$<$ PER002"> Pues venga, vamos, dale. (CREA; En una feria de barrio, Madrid, $08 / 08 / 91)$

\footnotetext{
${ }^{32}$ Para la denominación de las funciones interjectivas de vamos, tomamos la clasificación funcional que propone Cuenca (2001: 3215-3231), basada en las funciones comunicativas de Jakobson (1960): expresiva, conativa, fática, metalingüística y representativa.

${ }^{33}$ A estos valores, pueden sumarse valores pragmáticos vinculados con el estado emocional y mental del hablante en el momento de la enunciación (sorpresa, rechazo, enfado, etc.), que suelen añadirse de manera tangencial a los valores funcionales prototípicos en función de variables no controlables de la situación comunicativa.

${ }^{34}$ Constituyen también funciones genéricas de las construcciones discursivo-interactivas derivadas de vamos, entre otras [vamos que si + enunciado ecoico] o [A, pero vamos, $\left.\mathrm{A}^{\prime}\right]$ :

Pues sí que está bueno, sí, vamos que si está bueno. (refuerzo ilocutivo y acuerdo enfático)

Este tío está loco, pero vamos, loco perdido. (refuerzo ilocutivo-argumentativo)

Para una descripción detallada de las características gramaticales y semántico-funcionales de estas construcciones discursivas, véase Polanco, 2010.
} 
(10bis) Yo también te buscaré algo, aunque le di a mi sobrino, aun me quedan cosillas, solo falta que nos digas qué es... vamos, no te preocupes que seguro no le faltará nada. (http://www.foropadres.com/viewtopic.php?f=90\&t=8102)

Para poder determinar que los ejemplos anteriores muestran un sentido independiente distinto del sentido verbal, deben cumplirse al menos dos de los tres criterios aducidos en el apartado 3.1.1.: por un lado, que estos ejemplos proporcionan un significado adicional no presente en el sentido verbal (criterio semántico); y, por otro, que el sentido conativo presenta patrones de elaboración semántica distintos (criterio de elaboración semántica) y/o características gramaticales distintivas (criterio gramatical) respecto del sentido verbal.

\subsubsection{El criterio semántico}

A diferencia del sentido verbal, en los ejemplos (9bis) y (10bis) vamos expresa la intención del hablante de influir en la conducta de su interlocutor, bien para que este realice alguna acción que beneficia al hablante, bien para que modifique su actitud psicológica, generalmente en beneficio del interlocutor. De acuerdo con el criterio semántico, las ocurrencias anteriores apuntan a una lectura modal deóntica (exhortación), en la que la instrucción del movimiento espacial ha dejado de interpretarse. Ahora, el valor que prima es la exhortación a realizar una determinada acción; esto es, se focaliza la meta del movimiento (la voluntad del hablante) y el papel del interlocutor en la consecución de la meta, dejando al sujeto hablante, implícito en el morfema plural de vamos, en un segundo plano.

\subsubsection{El criterio de elaboración semántica}

La lectura conativa se interpreta en contextos en los que vamos no indica ya un movimiento en el espacio, sino en los que se focaliza la voluntad del hablante de que se realice determinado evento o de que cambie un determinado estado de cosas. Este nuevo sentido modal (deóntico ${ }^{35}$ ) se elabora en términos de una reconceptualización del movimiento espacial en movimiento volicional (en la mente del oyente), a partir del refuerzo contextual del valor exhortativo implícito en la forma subjuntiva: se focaliza la

\footnotetext{
${ }^{35} \mathrm{~A}$ diferencia de otros autores, como Martín Zorraquino (1999), quien reserva el término "marcador de modalidad deóntica" para los marcadores que expresan el acuerdo con el interlocutor, en este trabajo tomamos una concepción de la modalidad deóntica menos restrictiva, tal como la define Palmer (1986), que permite incluir las formas que codifican la intención del emisor de influir sobre el destinatario (Gras et al., 2005).
} 
intención del hablante de conseguir cierta meta (la realización de una acción real o mental) mediante un cambio de posición actitudinal por parte del oyente (movimiento volicional) y no el movimiento para alcanzar cierta meta. El sentido conativo puede funcionar como un acto de habla independiente, cuando se sobreentiende contextualmente la acción exhortada, aunque suele ir acompañado de un acto de habla directivo que explicita dicha acción.

La implicatura convencional que se deriva con el uso conativo de vamos puede parafrasearse como

El hablante quiere que haga esto [la acción expresada en el acto de habla directivo que acompaña a vamos o la acción implícita a que la que apunta vamos, si esta ha sido expresada por otro (inter)locutor o se sobreentiende contextualmente].

\subsubsection{El criterio gramatical}

Según este criterio, relativo a la distintividad gramatical, el sentido conativo muestra claramente un comportamiento gramatical diferenciado respecto del sentido verbal. Como acabamos de señalar, el vamos conativo se interpreta en contextos en los que el hablante exhorta al oyente a que realice determinada acción o cambie de actitud. A diferencia del vamos verbal, el vamos conativo:

(i) no concuerda con el sujeto de la cláusula que representa el evento que debe realizarse (Vamos ${ }^{*}$ [nosotros], ve tú primero ${ }^{36}$;

(ii) no admite complementos verbales, y si aparecen argumentos modales, temporales o locativos, estos dependen del verbo del enunciado directivo (Vamos, deprisalya,

\footnotetext{
${ }^{36}$ Podría argüirse que este argumento es relativamente cierto, en tanto que sí puede haber concordancia entre vamos y el sujeto de la oración que representa el evento que debe realizarse, como parecen demostrar ejemplos del tipo Vamos, calmémonos todos o Vamos, comeremos nosotros primero. Sin embargo, esta concordancia es aparente, ya que en los ejemplos anteriores vamos no representa una acción acorde al lexema verbal (no se exhorta al movimiento), dado que la realización de la acción de la oración siguiente no implica un movimiento o desplazamiento para su consecución. En realidad, aunque vamos sigue implicando una primera persona del plural, en tanto que el hablante queda incluido, tal como se desprende de la interpretación de las formas verbales de las oraciones que siguen a vamos, ya no se interpreta un valor verbal, sino un valor modal de exhortación a la realización de la acción indicada por el acto de habla directivo que acompaña a vamos. Por otra parte, en los ejemplos anteriores no puede sustituirse vamos por formas verbales afines sin que el resultado produzca extrañeza o agramaticalidad: ${ }^{*}$ Marchemos/Partamos, calmémonos todos. En cambio, vamos, como forma interjectiva conativa que es, sí puede aparecer acompañada de otras interjecciones equifuncionales, a modo de refuerzo ilocutivo: Vamos,venga/va, calmémonos todos; o sustituirse por otra interjección de función similar: Venga, comeremos nosotros primero.
} 
acaba que lo necesito; Vamos, (andando/vete) para casa rápidamente, que te esperan hace rato);

(iii) no admite sujeto; en caso de que aparezca un SN susceptible de interpretarse como sujeto, que puede ser tanto prototípico como no prototípico (Vamos, cacharro asqueroso, arranca ya [aludiendo a un ordenador, por ejemplo]), lo hace separado por pausa de vamos y del enunciado directivo, o pospuesto a este, y o bien no presenta concordancia con ningún elemento del enunciado (Vamos, muchacho, que nos esperan), o bien concuerda con el verbo del enunciado directivo (Vamos, tú, que no te enteras);

(iv) no admite negación $\left({ }^{\star}\right.$ No vamos, espabila);

(v) no admite paráfrasis mediante elementos verbales afines ( ${ }^{*}$ Partamos/ Dirijámonos/marchemos, no te preocupes, que todo pasa), pero puede coaparecer con formas interjectivas conativas deverbales (Vamos, va/venga, adelanta ya /Anda, vamos, no te lo tomes asî).

Por otro lado, el vamos conativo muestra un comportamiento prototípicamente interjectivo y responde afirmativamente a los rasgos que caracterizan a las interjecciones frente a otros elementos discursivos no interjectivos, a saber:

(i) Puede constituir (y generalmente así lo hace) un enunciado autónomo no elíptico; cuando se acompaña de un acto de habla directivo que expresa la "acción" que debe realizar el interlocutor, el vamos conativo presenta una curva entonativa independiente del acto de habla directivo.

(ii) Tiene significado modal (modalidad deóntica): expresa la intención del hablante de influir en la conducta de su interlocutor.

(iii) Tiene entonación marcada.

(iv) En estilo indirecto, puede separarse del miembro discursivo que le sigue mediante la conjunción que (Portolés, 2001: 69-70).

De lo anterior se sigue que el vamos conativo ha cancelado su sintaxis verbal (Company, 2004a) y muestra un comportamiento claramente interjectivo: constituye una unidad semántica y comunicativa, puede aparecer solo ocupando turno como enunciado autónomo no elíptico y se acompaña de enunciados con verbo en forma imperativa (actos de habla directivos). En definitiva, los tres criterios considerados permiten asumir que la lectura conativa de vamos (ejemplos 9bis y 10bis) constituye un sentido independiente. 


\subsubsection{Derivación del sentido conativo}

El paso de un significado espacial a otro modal deóntico parte de un cambio en el foco de atención del hablante-oyente y se fundamenta en el refuerzo de significados modales secundarios implícitos en el uso de la forma verbal que en determinados contextos empiezan a cobrar mayor peso interpretativo. La voluntad de negociar la interacción emisor-receptor y, posteriormente, de regular la comunicación implicitan un refuerzo progresivo tanto de la subjetividad del hablante en su enunciación, como de la informatividad (strengthening of informativeness, Traugot y König [1991]). Este cambio semántico es de carácter metonímico, en tanto que surge de la focalización y refuerzo en determinados contextos de significados contiguos que actuaban en un segundo plano interpretativo (refuerzo implicatural).

Así, puede defenderse que la interpretación conativa (modal deóntica) se deriva de una implicatura conversacional a partir de una interpretación no estereotípica del uso verbal de vamos. A partir del momento en que vamos no alude a un movimiento físico conjunto (que sería la situación estereotípica señalada por la forma verbal), sino que exhorta al hablante a realizar una determinada acción solicitada por el hablante, el oyente reinterpreta el valor verbal de desplazamiento hacia un valor modal deóntico: ahora lo que debe moverse es la voluntad del oyente para realizar un cambio de actitud o llevar a cabo un acción conforme con la voluntad del hablante. Es decir, se refuerza el valor modal implícito en la forma verbal y se focaliza en el sujeto hablante. El movimiento y cambio de posición del oyente parten de la posición del hablante, de su voluntad, en tanto que la finalidad es satisfacer el acto directivo explícito o implícito que acompaña a vamos. En este sentido, persiste de algún modo el significado original de desplazamiento conjunto de hablante y oyente.

En cualquier caso, como apuntábamos antes, no resulta sencillo determinar si lo metafórico facilita el refuerzo de ciertos implícitos, o si este refuerzo activa una reconceptualización metafórica del valor verbal originario. Tal como intentamos esquematizar a continuación, podría defenderse que a medida que se van reforzando ciertas implicaturas, se va afianzando la reconceptualización del movimiento espacial en movimiento volicional (cambio metafórico): 
DESPLAZARSE (EN EL ESPACIO) IMPLICA UN CAMBIO DE POSICIÓN PARA

ALCANZAR UNA META (hay un punto de origen, direccionalidad y un punto final)

(yo+tú (+otros)) • $\longrightarrow$ (meta locativa)

MOVERSE EL OYENTE POR SU MENTE IMPLICA UN CAMBIO DE POSICIÓN MENTAL PARA CONSEGUIR ALGO (lo que pide el hablante)

(yo) $\bullet$ tú/vos. $\longrightarrow \bullet$ (meta: acción o cambio de estado)

Implicatura conversacional: El hablante no va a moverse y yo tampoco tengo que moverme, no tengo que ir a ningún sitio; luego, lo que quiere el hablante es que haga algo (refuerzo del valor exhortativo implícito en la forma verbal), lo que pide con su enunciado es que cambie mi posición mental por la suya/sume mi posición mental a la suya.

\subsubsection{Vamos fático: el (des)acuerdo enfático}

Los siguientes ejemplos muestran el sentido fático de vamos: acuerdo (11) y desacuerdo (12):

(11)A: ¿Te gusta (mostrando un vestido)?

B: VAmos $\downarrow / \operatorname{vamo}(:) s \uparrow^{37}$

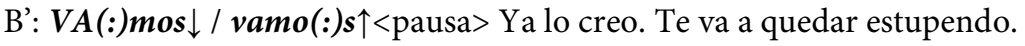

(12) SGAE: 'Ha habido una tergiversación de los hechos'

www.elmundo.es/elmundo/2009/05/28/catalejo/1243510544.html por su_r00t el 28-05-2009 13: 51 UTC, publicado el 28-05-2009 15: 15 UTC

"Ha habido una tergiversación de los hechos teñidos de mentiras y falsedades", asegura un representante de la SGAE sobre el peculiar acceso -y registro según el afectado- a la casa de Juan José Coronel. La sociedad se remite al acta levantada por el juez que entró en la casa y asegura que "no se ha infringido la legalidad".

\footnotetext{
${ }^{37}$ Con estas grafías representamos el esquema entonativo de vamos en función fática (ver tabla 1 y gráficos 1 y 2). Debido a la ausencia de ocurrencias de vamos con valor fático en el corpus analizado que presentaran un nivel acústico adecuado para realizar el análisis espectrográfico, los datos prosódicos que ofrecemos se fundamentan en un análisis espectrográfico realizado a partir de cinco elocuciones de hablantes distintos que expresaban ejemplos de réplica, acuerdo y acuerdo enfático. Con todo, reconocemos que estos datos son solo orientativos y requieren de un mayor número de acurrencias para asegurar su carácter prototípico. Asimismo, queremos agradecer la ayuda que nos brindó la Dra. Ana Fernández para la realización del análisis espectrográfico en el laboratorio de fonética de la Universidad de Barcelona.
} 
95 comentarios en: actualidad, sociedad karma: 774
etiquetas: sgae, juan josé coronel, registro, domicilio
negativos: 3 usuarios: 464 anónimos: 604 compartir:

\#1 "No se ha infringido la legalidad"..... anda, igual que con las descargas!!

votos: 86, karma: 754

por perga el 28-05-2009 13: 53 UTC

\#2 Conste que no la envío por defenderlos, más bien al contrario, los odio con todas mis fuerzas. Es para que veamos lo rápido que han saltado acojonados. Para otras cosas bien que se callan

votos: 36 , karma: 341

por su_r00t el 28-05-2009 13: 55 UTC

\#3 Pues tienen razón, hay tergiversación, se la estamos leyendo en este meneo.

votos: 14, karma: 137

por ronko el 28-05-2009 13: 55 UTC

\#12 Vamos no me jodas!!!! QUE LES DENUNCIE A LOS 5, por cierto ¿quien es el hijo de puta que ni siquiera se identifico? y ahora a decir que se han transgiversado las cosas, y un huevo!!!! QUE LOS DERECHOS DE AUTOR LOS RECAUDEN LAS PUTAS, QUE SUS HIJOS MIRA LA QUE ESTAN MONTANDO.

votos: 16, karma: 142

por aitorbs_el 28-05-2009 14:05 UTC

(http://meneame.net/story/sgae-ha-habido-tergiversacion-hechos)

\subsubsection{El criterio semántico}

Tal como muestran los ejemplos anteriores, vamos indica la actitud del hablante respecto del oyente y su enunciación, bien para mostrar acuerdo (11), bien para mostrar desacuerdo (12); las ocurrencias anteriores apuntan, pues, a una lectura modal deóntica. A diferencia del vamos conativo, que también codifica un valor modal deóntico, el vamos fático no expresa una exhortación a realizar una determinada acción (no es un acto directivo implícito), sino una valoración del estado de cosas expresado por un interlocutor real o potencial o de la situación comunicativa.

El vamos fático deriva, en nuestra opinión, una implicatura convencional que podría parafrasearse como

El hablante cree que [lo que digo/lo que dice X/el estado de cosas X] es [muy aceptable/inaceptable]. 


\subsubsection{El criterio de elaboración semántica}

El valor fático que acabamos de comentar se elabora prototípicamente a partir de contextos dialógicos en los que el hablante manifiesta en una intervención reactiva su valoración sobre lo dicho, ordenado o preguntado por otro en un turno iniciativo previo, o respecto de un estado de cosas explícito o implícito en el contexto comunicativo. El vamos fático puede ir acompañado de actos de habla justificativos con los que el hablante contextualiza las razones de su (des)acuerdo. Por el contrario, el valor conativo, que también se elabora prototípicamente en contextos dialógicos, constituye generalmente una intervención iniciativa o reactivo-iniciativa con la que el hablante trata de modificar un estado de cosas o la actitud de su interlocutor y suele introducir actos de habla directivos que explicitan la acción o el cambio deseados por el hablante. En este sentido, puede establecerse que ambos usos interjectivos de vamos despliegan interpretaciones estables diferenciadas: en el primer caso, valorar la proposición expresada por un (inter)locutor distinto del hablante, mostrando (des)acuerdo; en el segundo caso, modificar un estado de cosas o la actitud del interlocutor.

Ambos valores, el conativo y el fático, retienen en parte el sentido exhortativo original, en tanto que no deja de percibirse implícitamente una invitación al interlocutor a participar de la intención comunicativa del hablante. Este valor implícito de cooperación intersubjetiva entre hablante y oyente podría considerarse, como hacen algunos autores $^{38}$, el sentido de base de esta interjección. En este sentido, tanto la interpretación conativa como la fática se entenderían como elaboraciones contextuales a partir de este valor cooperativo. No obstante, como trataremos de demostrar más adelante en la descripción del valor formulativo (\$4.1.3), el sentido de cooperación se interpreta, más bien, como una implicatura generalizada a partir del valor inclusivo de vamos. Como tal implicatura, puede cancelarse contextualmente, sobre todo en contextos replicativos en los que el hablante muestra su desacuerdo con el interlocutor.

\subsubsection{El criterio gramatical}

El vamos fático ha perdido su capacidad sintáctica verbal originaria (no selecciona argumentos, no puede negarse ni parafrasearse por otro elemento verbal con un significado similar) y muestra un comportamiento prototípicamente interjectivo:

\footnotetext{
${ }^{38}$ Por ejemplo, Martín Zorraquino (Martín Zorraquino y Portolés, 1999) y Chodorowska (1999).
} 
1) Aparece en contextos sintáctico-conversacionales ocupando turno indepediente como intervención reactiva a un acto iniciativo previo formulado por otro interlocutor; puede acompañarse de actos justificativos que no exhortan directamente al hablante a realizar una acción o a modificar su actitud.

2) Tiene significado modal (modalidad deóntica): expresa el rechazo o la aceptación-confirmación del punto de vista o la propuesta de otro (inter)locutor o de un determinado estado de cosas.

3) Tiene un contorno prosódico marcado que se asocia convencionalmente con alguno de los dos valores fáticos mencionados.

4) En estilo indirecto, puede separarse del miembro discursivo que le sigue mediante la conjunción que.

Por otro lado, como tratamos de mostrar en la tabla 1, el vamos fático se diferencia del vamos conativo en varios rasgos co(n)textuales: representa un acto reactivo, constituye un acto valorativo no directivo, puede acompañarse de actos justificativos no exhortativo, expresa aceptación o rechazo y presenta rasgos prosódicos estables.

\begin{tabular}{|c|c|}
\hline vamos fático & vamos conativo \\
\hline $\begin{array}{l}\text { - Constituye un acto reactivo } \\
\text { - Constituye un acto valorativo no directivo } \\
\text { no exhortativos } \\
\text { - Expresa rechazo o aceptación de un punto } \\
\text { de vista ajeno } \\
\text { - Presenta rasgos prosódicos estables y siste- } \\
\text { matizables: pico tonal de la primera sílaba y } \\
\text { entonación descendente final (gráfico 1). } \\
\text { Asimismo, cuando vamos expresa un acto } \\
\text { de confirmación, de mostración enfática del } \\
\text { acuerdo, puede presentar una ligera varia- } \\
\text { ción en el esquema entonativo: entonación } \\
\text { circunfleja }{ }^{39} \text { final, con ligero alargamiento } \\
\text { de la última vocal de vamos/vaya (gráfico } \\
\text { 2). }\end{array}$ & $\begin{array}{l}\text { - Constituye un acto iniciativo o reactivo- } \\
\text { iniciativo } \\
\text { - Constituye un acto directivo implícito } \\
\text { - Suele introducir actos de habla directivos } \\
\text { que especifican la acción exhortada } \\
\text { - Expresa la intención del hablante de mo- } \\
\text { dificar la actitud de su interlocutor } \\
\text { - Presenta mayor variabilidad prosódica } \\
\text { (los rasgos prosódicos de este uso son } \\
\text { menos sistematizables) }\end{array}$ \\
\hline
\end{tabular}

Tabla 1. Rasgos diferenciales del vamos fático y conativo

\footnotetext{
${ }^{39}$ La entonación circunfleja implica un ascenso y descenso tonal en la misma sílaba (Martínez Celdrán y Fernández, 2007).
} 
Los rasgos prosódicos desempeñan un papel importante en la desambiguación semántica de esta interjección. Tal como defendemos en este trabajo, la entonación forma parte del conocimiento metalingüístico convencional que el hablante asocia con el uso e interpretación del vamos fático; esto es, el contorno prosódico constituye, junto con otros componentes de índole gramatical y pragmático-funcional, un rasgo especificado en el marco de interpretación asociado a esta interjección.

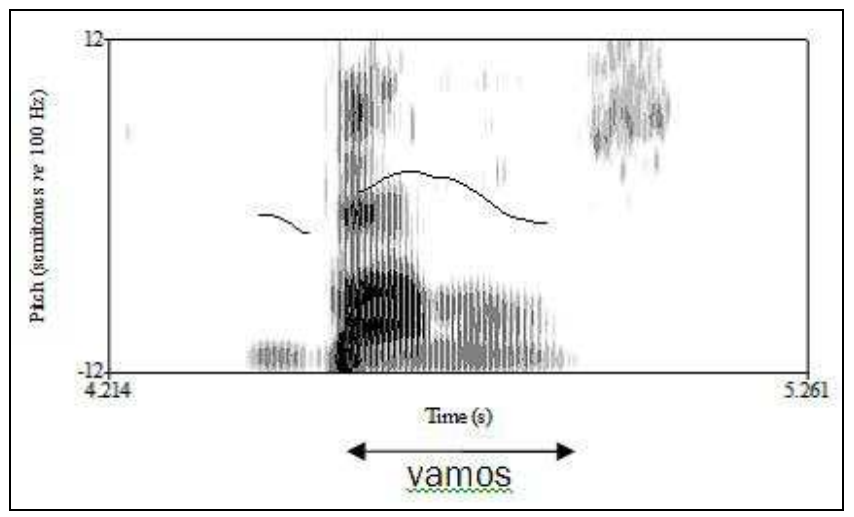

Gráfico 1. Espectograma de vamos en función fática

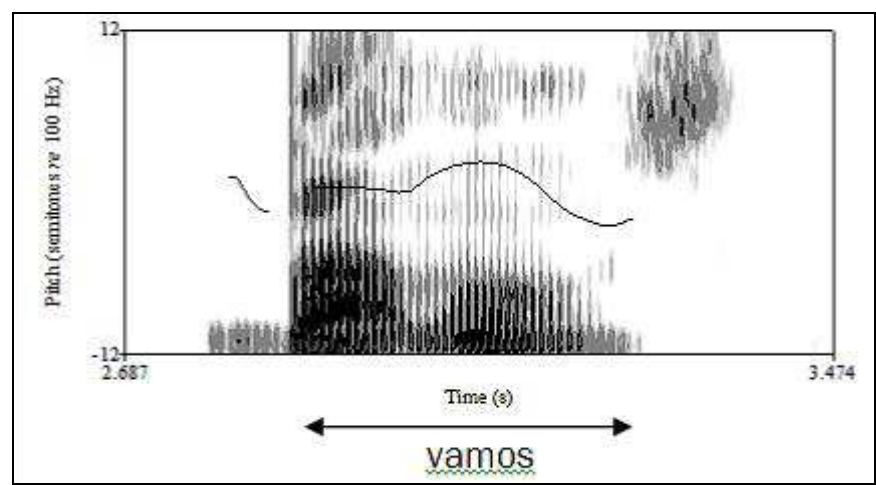

Gráfico 2. Espectograma de vamos circunflejo en función fática (acuerdo enfático)

En suma, los tres criterios considerados muestran un comportamiento gramáticofuncional y una interpretación estable de vamos en función fática que permiten considerarlo como un sentido independiente de la red semántica de la forma vamos. 


\subsubsection{Derivación del sentido fático}

La hipótesis explicativa que proponemos en este apartado se fundamenta principalmente en una reconstrucción pragmática basada en las diferencias contextuales que muestra el uso fático de vamos respecto del uso conativo ${ }^{40}$.

El valor fático podría haber surgido como una implicatura conversacional particularizada a partir del uso conativo en contextos no directivos, esto es, cuando vamos se utiliza para exhortar al interlocutor no a realizar alguna acción, sino a aceptar el punto de vista del hablante. El uso de vamos se produce, pues, en un contexto dialógico atípico que actúa a modo de escenario crítico (critical stage, [Diewald, 2002: 103]). Este nuevo escenario, según Diewald, produce ambigüedades estructurales y semánticas que invitan a una interpretación alternativa y funciona generalmente como estadio intermedio en la gramaticalización de nuevas estructuras (Traugott, 2010). En el caso que nos ocupa, el cambio de posición estructural de vamos (acto iniciativo + acto de habla directivo $>$ acto reactivo [+ acto de habla justificativo]) propicia su interpretación como reacción valorativa a lo expuesto por el interlocutor o a un estado de cosas explícito o implícito en el contexto comunicativo y se empieza a asociar este nuevo uso con la manifestación del (des)acuerdo del hablante.

\subsubsection{Vamos formulativo}

Los ejemplos (1)-(6) del apartado 1, que repetimos a continuación, muestran algunas ocurrencias de vamos con valor formulativo:

(1bis) O sea, en su momento, hubo tesis por las cuales el segundo canal iba a ser un canal que se podría haber financiado sin publicidad, vamos a costa del presupuesto, [...]. (CREA; Debate: las nuevas televisiones, 10/12/87, TVE 1)

(2bis) (...) luego viene Daniel, que Daniel es muy curioso<PAUSE $>$ bueno, tiene catorce años, es el pequeño de los niños, pero tiene un espabile encima, vamos, que ese sí que no parece que tiene catorce años porque es demasiado espabilado, se pasa de rosca, pero es supergracioso, nos partimos con él. (CREA; Entrevista CSC008, mujer, 20 años)

(3bis) [...] es que bueno, por no hacer muy extensiva la intervención en cuanto a los grupos, vamos, en cuanto a los factores de riesgo. (CREA; Debate: El Sida, 23/04/87, TVE 1)

\footnotetext{
${ }^{40}$ Esta hipótesis es claramente provisional y esperamos poderla confirmar en trabajos posteriores con datos diacrónicos de los que carecemos en el presente estudio.
} 
(4bis) y el de la autoescuela le dice pero tío pero ¿¡de qué vas $\downarrow$ !? ¿¡tú estás loco!?/ ¿cómo te vas-? si acabas de empeZAAR $\downarrow$ no has venío ningún día a CLASE/vamos o s(e)a// yo si quieres yo te apunto// tú eres el que vas a tener QUE PAGAR/ que me apuntes $\downarrow$ que me apuntes $\downarrow$ que me apuntes $\downarrow$ que me apuntes $\downarrow$ es cantidad de cabezón $\downarrow$ que me apuntes $\downarrow$ total quee lo puso de tal forma que lo tuvo que apuntar// yy ¿cuándo fue eel-? sí $\downarrow$ el- el martes pasado $\downarrow$ creo que fue examen (Briz y grupo Val.Es.Co, 2002: 113 [L.15.A.2])

(5bis) A: ¿yy alguna fiesta del barrio?// ¿de cuando eras pequeña?

B: yo no he ido- no he sido muy de barrio (chasquido)// pero vamos recuerdo las Fallas sobre todo las Fallas// es cuando más yo/ vamos cuando yo he trabaja(d)o más en eel- ¡uy! Perdón hee colabora $(d)$ o o he esta $(d) o$ así más en el barrio (...). (Preseval, [conv. 1, líneas 74-78]; http://www.uv.es/preseval/ppal.htm)

(6bis) Bueno, es decir, oye $<P A U S E>$ qué quieres, no sé. Dicen de que $<P A U S E>$ dicen Cruz y Raya de que yo hablo inseguro. Es que pienso que $<P A U S E>$ vamos, o sea, no estoy de acuerdo, pero $<$ PAUSE $>$ vamos, no sé, ¿no? O sea, yo creo $<P A U S E>$ yo que usted $<$ PAUSE $>$ vamos, no sé, ¿verdad, señor Gil?

Igual que con los sentidos verbal, conativo y fático, para poder determinar si los ejemplos anteriores muestran un sentido independiente, deben cumplirse al menos dos de los tres criterios que venimos aduciendo. Por un lado, que estos ejemplos proporcionan un componente semántico no presente en los sentidos descritos anteriormente (criterio semántico). Por otro, que el sentido formulativo presenta patrones de elaboración semántica distintos (criterio de elaboración semántica) o características gramaticales distintivas (criterio gramatical) respecto de los sentidos que hemos consignado en los apartados anteriores.

\subsubsection{El criterio semántico}

Las ocurrencias de vamos en los ejemplos anteriores muestran algunos de los distintos valores funcionales relacionados con la formulación discursiva, a saber, reformulación parafrástica (ejemplo 1bis), reformulación recapitulativa (ejemplo 2bis), reformulación rectificativa (ejemplo 3bis), rearticulación comentadora (ejemplo 4bis), rearticulación relanzadora (ejemplo 5bis) y rearticulación de relleno (ejemplo 6bis) ${ }^{41}$. Pese a la

\footnotetext{
${ }^{41}$ La función rearticuladora, como apuntamos en la nota 2, se vincula con la reorganización discursiva. Pero esta función reorganizativa puede llevarse a cabo mediante operaciones discursivas diferentes: (i) introducir un cambio de perspectiva enunciativa con el que se inicia un nuevo tópico para aclarar o matizar la intención del decir (rearticulación comentadora o digresiva); (i) impulsar el habla tras un titubeo más o menos apreciable, concluyendo la unidad discursiva que ha quedado incompleta antes
} 
divergencia funcional que presentan los ejemplos anteriores, todos ellos apuntan hacia una interpretación funcional de base especializada en la formulación discursiva. Este valor se interpreta como valor de fondo en todas las ocurrencias del corpus analizado, lo cual permite pensar en el sentido de formulación como en uno de los sentidos básicos de la red semántica que proponemos para vamos.

A diferencia de los sentidos propuestos en los apartados anteriores, el sentido de formulación ya no implica un desplazamiento físico del hablante [y otros] (sentido ver$b a l)$, ni expresa la intención del hablante de influir en la conducta de su interlocutor (sentido conativo), así como tampoco muestra el (des)acuerdo del hablante respecto del interlocutor (sentido fático). El significado de formulación retiene en parte el significado de prospección relacionado con la instrucción verbal de origen, pero orientado ahora hacia un espacio virtual, el del discurso. A este valor de prospección discursiva subyacente, el marcador vamos añade un significado vinculado con su función discursiva más prototípica: la formulación. El hablante indica que el movimiento discursivo que señala el MD se realiza para añadir más información. Esta instrucción se derivaría de la anterior por un proceso de implicatura conversacional generalizada a partir del principio I[nformatividad] ("lo que se dice de manera estereotípica, se interpreta de manera estereotípica", Levinson, 2004) que acaba por convencionalizarse: El hablante se mueve y me pide que me mueva con algún propósito. En el discurso, este propósito es el de añadir más información.

\subsubsection{El criterio de elaboración semántica}

La indicación ostensiva de un movimiento prospectivo en el discurso se interpreta como una marca de relevancia informativa orientada al interlocutor (una llamada de atención al interlocutor, función fática) y al enunciado (focalización) ${ }^{42}$. Esta llamada de atención implicita la intención del hablante de hacer algo, dado que el movimiento se realiza con alguna finalidad. En el espacio discursivo, la finalidad de avanzar en el discurso se relaciona con la ampliación de información. Esta inferencia, que podríamos parafrasear como El hablante quiere avanzar en el discurso [y me exhorta/invita a acompañarlo] porque quiere decir algo más, aparecería en un principio como una implicatura conversacional particularizada (como una implicatura débil) que se va afianzando en

del marcador (rearticulación de relanzamiento); o (iii) rellenar silencios potenciales, a modo de pausa oralizada, en contextos de habla discontinua (rearticulación de relleno) (Polanco, 2010: \$5).

${ }^{42}$ Pons (1998) también advierte una función similar en elementos interjectivos como mira y oye, a la que denomina función fática interna. 
la medida en que la exhortación al movimiento se reinterpreta como un avanzar conjunto del hablante y su(s) interlocutor(es) dentro del espacio discursivo, esto es, cuando la atención del interlocutor se dirige hacia el objeto discursivo.

En contextos discursivo-textuales, la exhortación al movimiento se reinterpreta como un movimiento virtual dentro de un espacio también virtual, de modo que la instrucción original subyacente (Desplacémonos desde el lugar X hasta el lugar Y para realizar Z) se elabora en términos metafóricos como un desplazamiento desde una posición enunciativa a otra para realizar una acción discursiva determinada (reformular o rearticular el propio discurso). Se trata, además, de una implicatura convencionalizada, y no generalizada, porque no es cancelable y se mantiene estable en todos los usos discursivo-textuales de este marcador.

El valor inclusivo de vamos, que hemos representado en la paráfrasis del valor formulativo como [y me exhorta/invita a acompañarlo], ha sido considerado por algunos autores como el valor que define la función principal de este marcador, a saber, la de reforzar la imagen positiva del hablante (Martín Zorraquino y Portolés, 1999: 41774180; esta autora clasifica a vamos entre los marcadores enfocadores de la alteridad), es decir, como un marcador discursivo interpersonal (Chodorowska-Pilch, 1999).

En nuestra opinión, el valor cooperativo de animar al interlocutor a sumarse a la perspectiva enunciativa del hablante que propone Martín Zorraquino (o, según nuestra propuesta, la invitación al oyente a acompañar al hablante en su movimiento prospectivo en el espacio del discurso), es un implícito que se deriva del significado inclusivo del marcador y que, en principio, se interpreta por defecto a partir del valor plural del marcador. Ahora bien, como demuestra el análisis en corpus, este valor puede neutralizarse en función de las variables de la situación comunicativa, sin que la eliminación de la lectura cortés distorsione en absoluto la función (re)formulativa, que permanece en todos los contextos analizados. Esto es lo que ocurre, por ejemplo, en los siguientes casos:

(13) Pero qué dices, hombre, eso no es así; vamos, que no es verdad.

(14) Pero tú eres tonto, de verdad; vamos, tonto perdido.

En estos ejemplos, vamos introduce una reformulación (16) y un refuerzo del enunciado previo al marcador (17) que matiza la valoración negativa que expresa el hablante, además de otros posibles valores modales de carácter expresivo en función del patrón entonativo. Sin embargo, la reformulación es potencialmente lesiva para el oyente: en ambos casos, hay un refuerzo, y no una mitigación, de la fuerza expresiva del enunciado reformulado. En consecuencia, el deseo de implicar a todos los interlocutores en la misma perspectiva enunciativa, como sugiere Martín Zorraquino, es, a nuestro enten- 
der, dudoso, puesto que difícilmente se sumará el oyente a la "perspectiva enunciativa del hablante" cuando esta es sumamente lesiva para él. Igualmente, el refuerzo ilocutivo que imprime vamos al enunciado reformulador tampoco contribuye a salvaguardar las imágenes del interlocutor, contrariamente a lo que propone Chodorowska-Pilch (1999).

Todo lo anterior impide, pues, la consideración del valor cooperativo de vamos como sentido central del marcador o como un valor codificado por este. Con todo, no puede obviarse que este valor inclusivo persiste en el significado del marcador a partir de la forma morfológica de plural, valor que se interpreta - cuando es relevante contextualmente- como una estrategia interactiva para integrar al interlocutor en la perspectiva del emisor. Ahora bien, pese a que el valor inclusivo de vamos es un valor implícito que se activa por defecto, es cancelable, esto es, puede anularse contextualmente. Por ello, consideramos que es mejor tratar el valor cooperativo de vamos como una implicatura conversacional generalizada (Levinson, 2004).

En suma, puede decirse que vamos establece la intención manifiesta del hablante de avanzar en el discurso ( $y$ contextualmente la intención de sumar al interlocutor en dicho avance, esto es, a su punto de vista) para realizar algún tipo de acción discursiva relacionada con la formulación.

\subsubsection{El criterio gramatical}

El vamos formulativo muestra un comportamiento gramatical claramente diferenciado tanto del vamos verbal, como del vamos interjectivo (conativo y fático). Por una parte, pese a conservar parte del significado léxico de origen relacionado con la prospección discursiva, el vamos formulativo no mantiene ninguna de las características verbales originales: no puede seleccionar argumentos de ningún tipo, ni admite la negación ni la paráfrasis con elementos verbales afines. Por otra parte, a diferencia de lo que ocurre con el vamos conativo y fático, cuya posición estructural prototípica en un contexto dialógico es una intervención iniciativa y reactiva, respectivamente, el vamos formulativo aparece prototípicamente en contextos pragmático-discursivos monológicos que no constituyen una respuesta reactiva a la intervención de otro locutor ${ }^{43}$. Asimismo,

${ }^{43}$ El uso de vamos (que) en contextos dialógicos de heterorreformulación puede adquirir un valor replicativo cuando la conclusión que explicita el hablante evidencia el rechazo o una contraexpectativa respecto del estado de cosas representado implícitamente en el acto de habla de su interlocutor:

A: ¿Has traído lo que te dije?

B: Pues, verás, es que...

A: Vamos, que te has olvidado. Si es que siempre me haces lo mismo. 
el vamos formulativo tampoco responde a los rasgos prototípicos que caracterizan a la interjección:

(i) No constituye un enunciado autónomo; como sugiere Wilkins a propósito de otras interjecciones con función discursiva (1992: 126, nota 5), el vamos formulativo presenta un grado elevado de integración prosódica en la curva entonativa del enunciado (re)formulador.

(ii) No tiene valor modal (salvo en la función de refuerzo ilocutivo-argumentativo, en que el valor modal epistémico se interpreta como una implicatura generalizada $)^{44}$, sino metadiscursivo.

(iii) No presenta una entonación marcada como rasgo inherente (aunque el patrón discursivo del marcador puede verse modificado contextualmente para expresar valores pragmáticos puntuales, como sorpresa, rechazo, enfado, etc.).

En definitiva, los tres criterios considerados permiten asumir que la lectura formulativa constituye un sentido independiente de la red semántica de vamos.

\subsubsection{Derivación del sentido formulativo}

La evolución del sentido verbal al sentido formulativo de vamos, igual que ocurría con el sentido conativo, participa tanto de una extensión metafórica del ámbito semántico y de uso original, como de un refuerzo de implicaturas derivadas de usos no convencionales.

Por un lado, se produce una ampliación metafórica del significado fuente desde un ámbito físico, en el que el movimiento se realiza en un espacio físico real (Yo y otros nos movemos desde aqui hasta otro lugar distinto del espacio que ocupamos), hacia un ámbi-

También se puede interpretar un valor replicativo en contextos monológicos de carácter polifónico en los que el hablante muestra el rechazo respecto de un punto de vista ajeno que no reproduce lo dicho por el interlocutor, sino por un tercero:

Que vaya a la central, que recoja el pedido, que lo lleve al destinatario, no te lo pierdas, en Gerona, y que luego vuelva a la central a recoger los pedidos que vayan entrando entretanto... Y eso a la una y media. Vamos, que se deben pensar que todo eso se hace en un plis.

En estos contextos, pese a que se interpreta contextualmente un valor fático de desacuerdo, creemos que sigue primando la función reformulativa, en tanto que el hablante formula una conclusión que se deriva implícitamente de la situación comunicativa.

${ }^{44}$ El valor epistémico de intensificación ilocutiva de vamos no forma parte de su significado, sino que es un implícito que surge como efecto de la marcación ostensiva del enunciado sobre el que incide el marcador y por la relación contrastiva paradigmática de vamos con otros elementos modales que podrían haberse utilizado en el mismo contexto (Polanco, 2010). 
to no físico, en el que el movimiento supone un cambio de posición virtual. Este cambio de posición puede realizarse o bien mediante una exhortación al oyente para que lleve a cabo una acción o un cambio de actitud, de modo que se produzca un movimiento volitivo por parte del oyente hacia la posición mental del hablante (función conativa y función fática de (des)acuerdo); o bien mediante un movimiento del hablante en el espacio virtual del discurso.

Además del cambio metafórico que se opera en el ámbito de actuación de este marcador, por el que se pasa de un dominio espacial a un dominio discursivo (mediante la metáfora EL DISCURSO ES UN ESPACIO [POR EL QUE MOVERSE]), también interviene un refuerzo implicatural. Este refuerzo de implicaturas conversacionales, como ocurría en el paso del valor verbal al valor conativo, se deriva también de un uso no estereotípico de vamos en contextos en los que no se alude a un movimiento espacial real, ni a la voluntad del hablante de influir en el oyente (salvo por el hecho de implicarlo con el plural morfológico del marcador). En estos nuevos usos de vamos, prima la voluntad del oyente de controlar el discurso, de regular el acto comunicativo y negociar la interacción con el interlocutor. Se interpreta, en suma, la intención del hablante de avanzar en el discurso y de mantener el turno de palabra para añadir información, al tiempo que trata de implicar al interlocutor en la acción discursiva, en su punto de vista. En cierto modo, como hemos apuntado antes, sigue persistiendo el significado original de desplazamiento conjunto a través de un espacio virtual, el propio discurso.

DESPLAZARSE (EN EL ESPACIO) IMPLICA UN CAMBIO DE POSICIÓN PARA

ALCANZAR UNA META (hay un punto de origen, direccionalidad y un punto final)

$($ yo+tú $(+$ otros $)) \bullet \longrightarrow \bullet($ meta locativa $)$

EL DISCURSO ES UN ESPACIO POR EL QUE NOS PODEMOS DESPLAZAR

(PROSPECTIVA O RETROACTIVAMENTE)

(yo)+(tú+otros) $\longrightarrow \bullet$ (meta discursiva: añadir información, mantener el turno)

Implicatura conversacional: El hablante y yo no vamos a movernos, no tenemos que ir a ningún sitio; luego, lo que quiere el hablante es avanzar en su discurso para añadir algo a lo que ya ha dicho; eso es posible porque de algún modo el discurso es como un espacio por el que nos movemos adelante para decir cosas, atrás para recuperar lo dicho, etc.

\subsection{Elaboraciones frente a sentidos}

En este trabajo, hemos centrado la atención en la descripción de los sentidos básicos de la red semántica de vamos. Estos sentidos básicos representan, como hemos tratado 
de demostrar, sentidos codificados de este elemento discursivo. No obstante, como apuntamos en el apartado 2.1.1, la interacción de un sentido básico con determinados contextos discursivos da lugar a diferentes elaboraciones de ese sentido con distintos grados de saliencia y de afianzamiento en la red semántica - y, en consecuencia, con un grado de dependencia variable del contexto de uso- en función del distinto grado de fijación del esquema discursivo en que aparece ${ }^{45}$.

Algunos de estos contextos presentan un grado elevado de estabilidad estructural y de fijación pragmático-discursiva que permite considerarlos como esquemas o construcciones discursivas asociados a determinadas interpretaciones construccionales por defecto (Polanco, 2010: \$7). Así, ciertas interpretaciones de vamos, entre ellas las de reformulación parafrástica o de equivalencia conceptual (ejemplo 1), recapitulativa o de síntesis conceptual (ejemplo 2) y rectificativa (ejemplo 3), pueden entenderse como sentidos construccionales inducidos por defecto por el esquema discursivo en que se insertan estos marcadores. Estas interpretaciones, pese al grado elevado de afianzamiento que presentan, constituyen, sin embargo, elaboraciones de un sentido afianzado más abstracto que las engloba, a saber, el sentido de formulación. Estas elaboraciones forman parte de la estructura semántica del sentido de base formulación y son componentes semánticos potenciales que se activan automáticamente en determinados contextos enunciativos (esto es, cuando el sentido de base interactúa con un esquema discursivo concreto) y se interpretan por defecto, como una implicatura generalizada, siempre que se utiliza en dicho contexto. En este sentido, puede concebirse que estas elaboraciones a partir del sentido de formulación de vamos son previsibles y están, en buena medida, especificadas en el marco de interpretación de la construcción y del propio elemento discursivo (Polanco, 2010: \$7.2.3.). Constituyen, pues, sentidos periféricos de la red semántica de vamos.

Las interpretaciones de reformulación parafrástica, rectificación y recapitulación, en tanto que diferentes formas de formular, pueden entenderse como facetas $^{46}$ del sentido

\footnotetext{
${ }^{45}$ El propósito de este apartado es el de presentar la potencialidad explicativa que puede tener un tratamiento construccional de los contextos funcionales de aparición de vamos para la descripción semántico-funcional de este tipo de elementos discursivos complejos. Por ello, en este apartado no ahondamos en los aspectos teóricos relacionados con el modelo gramatical de tipo construccional basado en el uso que defendemos en este trabajo, tarea que queremos desarrollar en futuros trabajos.

${ }^{46}$ Tomamos el concepto de Allan Cruse (Croft y Cruse, 2004). Con el concepto de faceta, este autor se refiere a ciertos sentidos de una palabra que presentan un grado notable de autonomía pero que necesitan de un contexto concreto para ser interpretados. Las facetas poseen autonomía relacional (cada faceta puede participar en sus propias relaciones de sentido, con independencia del comportamiento de otras facetas) y autonomía composicional (las facetas se relacionan composicionalmente con de-
} 
de formulación, esto es, como subpartes de un todo. En tanto que partes constitutivas del significado de vamos, dichas interpretaciones más concretas son componentes de significado del total semántico de la palabra $\mathrm{y}$, en buena medida, son aislables como tales componentes de significado, lo cual asemeja estas interpretaciones con los sentidos plenos.

Lo mismo puede decirse de algunas interpretaciones más concretas derivadas de alguno de los sentidos construccionales anteriores. Así, por ejemplo, las interpretaciones de recapitulación y conclusión que pueden adquirir marcadores de reformulación recapitulativa como en fin o en definitiva, o vamos y vaya cuando se utilizan en un contexto recapitulativo, pueden entenderse como elaboraciones de un sentido más abstracto, a saber, el de sintesis conceptual. La síntesis conceptual de un segmento discursivo previo puede realizarse bien recapitulando o resumiendo el contenido de ese segmento (15), bien explicitando una conclusión derivada explícita o implícitamente de ese contenido (16).

(15)Venga va aunque sean las tantas y sólo sea pa responder a Chelu, [los amish son algo así como el "Pirulas" pero mucho mas rústicos, vamos los tíos estos que van como los judíos ortodoxos, ya sabes en plan "skinetta". Sólo se alimentan de productos no manufacturados es decir los que se extraen directamente de las huertas, en las que trabajan con maquinaria primitiva, nada de M.C.I.A. y maquinaria pesada (como lo hacían nuestros tatarabuelos) y son muuuuuu respetuosos con el medio ambiente]. Vamos que [viven en el siglo XXI, pero actúan como si lo hiciesen a principios del XIX]. (http://es.groups.yahoo.com/group/ fortunetellersclub/message/3254)

(16) (...) /y yo la verdad es que con mi hermano y con mi cuñada me llevo muy bien / tengo una relación bastante agradable / y con los niños también / además los veo bastante / los saco a pasear / loos- vamos/ un día a la semana me encargo de ellos o sea que... (Preseval, [conv. 1, líneas 31-35])

En tanto que diferentes formas de sintetizar, las interpretaciones más concretas de recapitulación y conclusión pueden entenderse también como facetas del sentido de sintesis conceptual. No obstante, pese a que ambas lecturas presentan cierta autonomía relacional y composicional (ver nota 45), carecen de autonomía atencional (esto es, no

terminados elementos que afectan la interpretación de esa faceta concreta, es decir, que inciden solo en una porción del significado total del otro elemento). Sin embargo, no poseen autonomía atencional (no son unidades de sentido que se excluyan mutuamente), dado que pueden unificarse en una interpretación global o conjunta prototípica que las contiene, lo cual demuestra, según Cruse, que las facetas carecen de estatus pleno de sentido independiente (Croft y Cruse, 2004: 163). Para ser interpretados, estos sentidos dependen de un determinado contexto que los active. 
constituyen unidades de sentido que se excluyen mutuamente), puesto que pueden unificarse en un sentido más abstracto que las engloba, el sentido de síntesis conceptual. Ambas lecturas pertenecen, en buena medida, a tipos ontológicos diferentes (presentan una distancia semántica importante) y exhiben un grado de autonomía que induce a concebirlas como sentidos plenos; sin embargo, la posibilidad de unificación semántica justifica que no puedan considerarse estas interpretaciones como sentidos autónomos dentro de la red semántica. Se trata también, pues, de sentidos construccionales periféricos en la red semántica de vamos, con un grado de prototipicidad menor que los anteriores, dado que son el resultado de reinterpretaciones a partir de sentidos más genéricos.

Por último, algunas de las elaboraciones de un sentido particular son interpretaciones puntuales en situaciones comunicativas concretas. A diferencia de los sentidos construccionales, que son inducidos por las relaciones de solidaridad distribucional y composicional que mantienen el elemento léxico y un cotexto prototípico, las interpretaciones puntuales están sujetas a las variaciones que pueda presentar la situación comunicativa. Así ocurre, por ejemplo, con algunos de los valores pragmático-modales (enfado, irritación, resignación, etc.) y epistémicos (atenuación-refuerzo ilocutivo) de vamos, que pueden añadirse a otros valores discursivos (prototípicos) de este elemento en función de variaciones ocasionales en el patrón entonativo.

\subsection{Representación de la red semántica de vamos}

Como hemos tratado de demostrar en los apartados anteriores, la polifuncionalidad de vamos no es una mera cuestión de variación contextual a partir de un único significado invariante, sino que revela que este elemento discursivo despliega un rango de significados diferenciados en el nivel de la lengua. Estos valores funcionales de vamos (reformulación y rearticulación, función fática y función conativa; véase $\$ 3$ ) presentan un grado de autonomía y de saliencia elevados que permite considerarlos como significados independientes.

Estos significados, que representamos en círculos grises en la red polisémica de la figura 3, son extensiones diacrónicas del sentido verbal original (representado en un círculo negro), pero constituyen también sentidos centrales de la red semántica, en tanto que elementos semánticos independientes ligados a propiedades de selección semántica y gramatical diferenciadas. A su vez, estos significados centrales constituyen sentidos sancionadores de otros valores contextuales (representados en círculos blancos), con distinto grado de saliencia y afianzamiento dentro de la red polisémica. Estos valores contextuales, como hemos comentado en el apartado anterior, responden a 
interpretaciones construccionales derivadas de la interrelación entre el sentido central y determinados contextos prototípicos o esquemas discursivos (este vínculo por defecto se representa en la red semántica mediante una flecha continua).

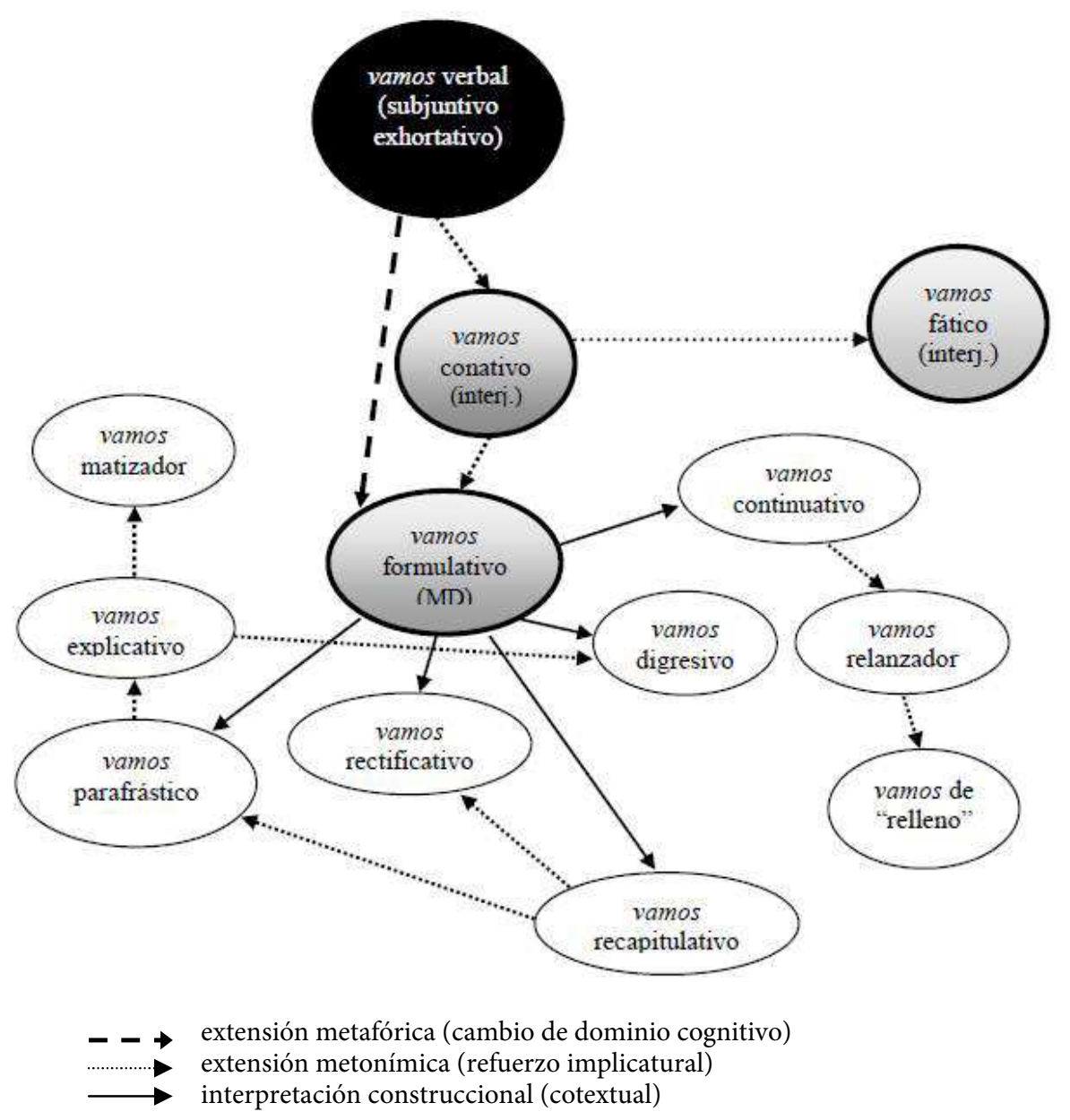

Figura 3. Red polisémicas (sincrónica) de vamos 


\section{Conclusión}

En este trabajo hemos defendido que la polifuncionalidad de vamos pone de manifiesto la naturaleza heterosémica de este tipo de elementos lingüísticos, esto es, su naturaleza policategorial y polisémica. Estos elementos, fuera de contexto, son formas lingüísticas acategoriales asociadas a un complejo, pero estructurado, entramado de rasgos sintácticos, semánticos, pragmático-discursivos y prosódicos. Solo cuando dichas formas lingüísticas se contextualizan, como hemos visto que ocurre en el caso de vamos, se activa una parte de su estructura de rasgos subyacente y podemos hablar entonces de un vamos verbal, interjectivo o marcador discursivo.

Por ello, la descripción semántico-funcional de elementos complejos como vamos requiere de modelos descriptivos que puedan mostrar de forma coherente y cohesionada (esto es, de forma integral) todos los rasgos funcionales que intervienen prototípicamente en el uso e interpretación de estos elementos. De ahí, en nuestra opinión, la idoneidad de aplicar un modelo polisémico radial a la descripción de vamos. Para su configuración, hemos adaptado el modelo propuesto por Evans (2004), el Modelo de polisemia fundamentada. Este modelo aporta la ventaja de proponer una serie de criterios falsables para el establecimiento de los sentidos codificados de las unidades lingüísticas polisémicas. En el caso de vamos, hemos partido de la idea de que este elemento constituye un emparejamiento convencional de forma y sentido, cuyo polo semántico se estructura en forma de una red semántica organizada en torno a tres sentidos básicos, a saber: el sentido conativo (relacionado con la voluntad de influir en la conducta del interlocutor), el sentido fático (relacionado con el (des)acuerdo) y el sentido formulativo (relacionado con las funciones metadiscursivas de (re)formulación). Estos significados son extensiones diacrónicas del sentido verbal como subjuntivo independiente original (representado en un círculo negro en la fig. 3), pero constituyen también sentidos centrales de la red semántica, en tanto que elementos semánticos independientes ligados a propiedades de selección semántica y gramatical diferenciadas.

Además de los sentidos convencionales que acabamos de mencionar, vamos activa determinados sentidos contextuales que parecen interpretarse por defecto, añadidos al significado nuclear, cuando este elemento forma parte de ciertos contextos funcionales prototípicos o esquemas funcionales (Polanco, 2010). Estas interpretaciones funcionales más específicas son el producto de la interrelación entre un determinado sentido básico o convencional y ciertos esquemas discursivos prototípicos y están fuertemente motivadas por esa interrelación. Estos sentidos, que hemos denominado sentidos construccionales, pueden concebirse como lecturas por defecto, en tanto que se activan automáticamente en función de dicha interrelación. Y son también, al mismo tiempo, interpre- 
taciones cancelables, esto es, interpretaciones que pueden anularse si existe presión contextual en una dirección interpretativa distinta. Por ello, pese a su fijación semántico-cognitiva, no son sentidos codificados, pero sí sentidos con un alto grado de convencionalidad, fácilmente accesibles en la memoria discursiva del hablante (esto es, en el marco de interpretación asociado a vamos). Son, pues, sentidos periféricos de la red semántica de vamos.

Recibido: 27-VII-2012

Aceptado: 25-I-2013

\section{Referencias bibliográficas}

Archakis, A. (2001): "On discourse markers: evidence from Modern Greek", Journal of Pragmatics, 33, págs. 1235-1261.

Blakemore, D. (1987): Semantic constraints on relevance. Oxford, Blackwell.

Blakemore, D. (1993): “The relevance of reformulations", Language and Literature, 2:2, págs. 101-102.

Blakemore, D. (2002): Relevance and linguistic meaning. The Semantics and Pragmatics of Discourse Markers. Cambridge, Cambridge University Press.

Boogart, R. (2009): "Semantics and pragmatics in construction grammar: The case of modal verbs". En Bergs, A. y G. Diewald (eds.): Contexts and Constructions. Amsterdam/Philadelphia, John Benjamins.

Brinton, L. J. (1996): Pragmatic markers in English. Grammaticalization and discourse functions. Berlin-New York, Mouton de Gruyter.

Briz, A. (1993a): "Los conectores pragmáticos en español coloquial (I): su papel argumentativo", Contextos, XI/21-22, págs. 145-188.

Briz, A. (1993b): "Los conectores pragmáticos en español coloquial (II): su papel metadiscursivo", Español Actual, 59, págs. 39-56.

Briz, A. (1998): El español coloquial en la conversación. Esbozo de pragmagramática. Barcelona, Ariel, 2001.

Brugman, C. (1988): The story of over: Polysemy, semantics and the structure of the lexicon. New York, Garland Press.

Brugman, C. y G. Lakoff. (1988): "Cognitive topology and lexical networks". En Small, S., Cottrell, G. y M. Tannenhaus (eds.): Lexical Ambiguity Resolution. San Mateo, CA, Morgan Kaufman, págs. 477-507.

Chodorowska-Pilch, M. (1999): "On the polite use of 'vamos' in Peninsular Spanish", Pragmatics, 9/3, págs. 343-356.

Company, C. (2004a): “¿Gramaticalización o desgramaticalización? Reanálisis y sub- 
jetivización de verbos como marcadores discursivos en la historia del español", RFE, LXXXIV, 1, págs. 29-66.

Company, C. (2004b): "Gramaticalización por subjetivización como prescindibilidad de la sintaxis", NRFH, 52:1, págs. 1-28.

Cortés, L. y M. M. Camacho (2005): Unidades de segmentación y marcadores del discurso. Madrid, Arco Libros.

Croft, W. (1998): "Linguistic evidence and mental representations", Cognitive Linguistics, 9, págs. 151-173.

Croft, W. y D. A. Cruse (2008): Cognitive Linguistics. Cambridge, Crambridge University Press.

Cuenca, Ma . J. (2001): "Los conectores parentéticos como categoría gramatical", LEA, XXIII: 2, págs. 211-235.

Cuenca, Ma. J. (2002): "Els connectors textuals i les interjeccions". En Solà. J y otros (dirs.): Gramática del català contemporani, vol. 3, cap. 31. Barcelona, Editorial Empúries, págs. 3173-3237.

Diewald, G. (2002): “A model for relevant types of contexts in grammaticalization”. En Wischer, I. y G. Diewald (eds): New reflections on Grammaticalization. Amsterdam, John Benjamins, págs. 103-120.

Evans, V. (2004): The structure of time: Language, Meaning and Temporal Cognition. Amsterdam, John Benjamins.

Evans, V. (2005): “The meaning of time: Polysemy, The Lexicon and Conceptual Structure", Journal of Linguistics, 41:1, págs. 1-39.

Evans, V. (2006): "Lexical Concepts, Cognitive Models and Meaning-Construction", Cognitive Linguistics, 17: 4, págs. 491-534.

Evans, V. (2009): How Words Mean: lexical concepts, cognitive models and meaning construction. Oxford, Oxford University Press.

Evans, V. y M. Green (2005): Cognitive Linguistics. An Introduction. Edinburgh, Edinburgh University Press.

Evans, V. y A. Tyler (2004a): "Rethinking English 'prepositions of movement' : the case of to and through". En Cuyckens, H. de Mulder, W. y T. Mortelmans (eds.): Adpositions of movement (special issue of the Belgian Journal of Linguistics 17). Amsterdam, John Benjamins, págs. 247-270.

Evans, V. y A. Tyler (2004b): "Spatial experience, lexical structure and motivation: the case of in". En Radden, G. y K-U. Panther (eds.): Linguistic studies in motivation. Berlin, Mouton de Gruyter, págs. 157-192.

Fischer, K. (2000a): From Cognitive Semantics to Lexical Pragmatics. The Functional Polysemy of Discourse Particles. Berlin and New York, Mouton de Gruyter.

Fischer, K. (2000b): "Discourse particles, turn-taking, and the semantics-pragmatics 
interface", Revue de Sémantique et Pragmatique, 8, págs. 111-137.

Fischer, K. (ed.) (2006a): Approaches to Discourse Particles. Studies in Pragmatics (vol. 1), Amsterdam, Elsevier.

Fischer, K. (2006b): "Frames, constructions and invariant meanings: the functional polysemy of discourse particles". En Fischer, K. (ed.), págs. 427-448.

Fischer, K. (2010): "Beyond the Sentence: Constructions, Frames and Spoken Interaction", Constructions and Frames, 2 (2), págs. 185-207.

Fuentes Rodríguez, C. (1987): Enlaces extraoracionales. Sevilla, Alfar.

Fuentes Rodríguez, C. (1998): "Vamos: un conector de gran complejidad". En Martín Zorraquino, Ma. A. y E. Montolío Durán (eds.), págs. 177-192.

Fuentes Rodríguez, C. (2009): Diccionario de conectores y operadores del español. Madrid, Arco Libros.

Geeraerts, D. (1993): "Vagueness's puzzles, polysemy's vagaries", Cognitive Linguistics, 4, págs. 223-272.

González Ollé, F. (2002): "Vamos. De subjuntivo a marcador (con un excurso sobre imos)". En Álvarez de Miranda, P. y J. Polo (eds.): Lengua y diccionarios. Estudios ofrecidos a Manuel Seco. Madrid, Arco Libros, págs. 117-135.

Gras, P., Polanco, F. y M. Santiago (2005): "Forma, función y evolución del marcador conversacional venga en español". En López Cano, P. (coord.): Actas VI Congreso de Lingüística General, págs. 1621-1635.

Hansen, M. M. (1998a): The Function of Discourse Particles. A study with special reference to spoken standard French, Amsterdam/Philadelphia, John Benjamins Publishing Company.

Hansen, M. M. (1998b): "The semantic status of discourse markers", Lingua, 104, págs. 235-260.

Hansen, M. M. (2005): "From propositional phrase to hesitation marker. The semantic and pragmatic evolution of French enfin", Journal of historical pragmatics, 6:1, págs. 37-68.

Hansen, M. M. (2006): "A dynamic polysemy approach to the lexical semantics of discourse markers (with an exemplary analysis of french toujours)". En Fischer, K. (ed.), págs. 21-41.

Lakoff, G. (1987): Women, Fire and Dangerous Things: What Categories Reveal About the Mind. Chicago, University of Chicago Press.

Langacker, R. (1987): Foundations of Cognitive Grammar I. Theoretical Prerequisites. Stanford, Standford University Press.

Loureda, O. y E. Acín (coords.) (2010): Los estudios sobre marcadores del discurso en español, hoy. Madrid, Arco Libros. 
Lyons, J. (1977): Semantics. Cambridge, Cambridge University Press.

Lyons, J. (1997): Semántica lingüistica. Una introducción. Barcelona, Paidós.

Martín Zorraquino, Ma . A. y E. Montolío Durán (coords.) (1998): Los marcadores del discurso. Teoría y análisis. Madrid, Arco Libros.

Martín Zorraquino, Ma . A. y J. Portolés (1999): "Los marcadores del discurso". En Bosque, I. y V. Demonte (dirs.): Gramática descriptiva de la lengua española, vol. 3. Madrid, Espasa Calpe, págs. 4051-4213.

Matsui, T. (2002): "Semantics and pragmatics of a Japanese discourse marker dakara (so/in other words): a unitary account", Journal of Pragmatics, 34, págs. 867-891.

Montolío Durán, E. (1998): "La Teoría de la Relevancia y el estudio de los marcadores discursivos”. En Martín Zorraquino, M. A. y E. Montolío Durán (eds.), págs. 177192.

Montolío Durán, E. (2001): Conectores de la lengua escrita. Barcelona, Ariel.

Murillo, S. (2000): "English explicatory reformulative discourse markers: Conceptual or procedural?". En Navarro, M. P. y otros (eds.): Transcultural Communication: Pragmalinguistic Aspects. Zaragoza, Anubar, págs. 131-138.

Murillo, S. (2004): “A relevance reassessment of reformulation markers”, Journal of Pragmatics, 36, págs. 2059-2068.

Nemo, F. (2002): "But (and Mais) as Morpheme(s)”, D.E.L.T.A., 18, págs. 87-114.

Nemo, F. (2006): "Discourse Particles as Morphemes and as Constructions". En Fischer, K. (ed.), Approaches to Discourse Particles, vol. 1 de Studies in Pragmatics, Amsterdam, Elsevier, págs.

Polanco, F. (2010): Variación funcional y polisemia. Marcadores conversacionales procedentes de verbos de movimiento: el caso de vamos y vaya. Tesis doctoral. Departamento de Filología Hispánica. Universidad de Barcelona.

Pons Borderia, S. (1998): Conexión y conectores. Estudio de su relación en el registro informal de la lengua. Cuadernos de Filología, anejo 27. Valencia, Universitat de València.

Pons Borderia, S. (2006): "A functional approach to the study of discourse markers". En Fischer, K. (ed.), págs. 77-99.

Portolés, J. (2001): Marcadores del discurso. Barcelona, Ariel, 1998.

Portolés, J. (2004): Pragmática para hispanistas. Madrid, Síntesis.

Redeker, G. (1990): "Ideational and pragmatic markers of discourse structure", Journal of Pragmatics, 14, págs. 367-381.

Redeker, G. (1991): "Linguistic markers of discourse structure”, Linguistics, 29, págs. 1139-1172.

Romero Aguilera, L. (2006): "La gramaticalización de verbos de movimiento como 
marcadores del discurso: el caso de vamos", Res Diacronicae, 5, págs. 46-56.

Sandra, D. (1998): "What linguists can and can't tell you about the human mind: a reply to Croft", Cognitive Linguistics, 9: 4, págs. 361-378.

Sandra, D. Y S. Rice (1995): "Network analices of prepositional meaning: mirroring whose mind the linguist's or the language user's?", Cognitive Linguistics, 6:1, págs. 89-130.

Schourup, L. (2001): “Rethinking 'well'”, Journal of Pragmatics, 33, págs. 1025-1060.

Sweetser, E. (1990): From Etymology to Pragmatics: Metaphorical and Cultural Aspects of Semantic Structure. Cambridge, Cambridge University Press.

Taylor, J. (2003): Linguistic categorization: prototypes in linguistic theory. Oxford, Oxford University Press.

Toledo Huerta, A. (2001): “¿Un viaje de ida y vuelta?: la gramaticalización de vaya como marcador y cuantificador”, Anuari de Filologia, XXIII, F: 11, Barcelona, Universitat de Barcelona, págs. 39-63.

Traugott, E. C. (1997): "The role of the development of discourse markers in a theory of grammaticalization" (conferencia leída en la $12^{\text {th }}$ International Conference on Historical Linguistics, Manchester, 1995; version escrita de noviembre de 1997): http://www.stanford.edu/ traugott/papers/discourse.pdf (23-03-2007]).

Traugott, E. C. (2010): "Contexts and gramatical constructions". Comunicación en el 6th International Conference on Construction Grammar (ICCG-6), Praga, septiembre de 2010.

Traugott, E. C. y E. König (1991): “The Semantic-Pragmatics of Grammaticalization Revisited”. En Traugott, E. C. y B. Heine (eds.): Approaches to Grammaticalization. Amsterdam, John Benjamins, págs. 189-218.

Travis, C. E. (2005): Discourse Markers in Colombian Spanish: A Study in Polysemy. Berlin/New York, Mouton de Gruyter.

Travis, C. E. (2006): "The natural semantic metalanguage approach to discourse markers”. En Fischer, K. (ed.), págs. 219-241.

Tyler, A. y V. Evans (2001): "Reconsidering prepositional polysemy networks: the case of over", Language, 77: 4, págs. 724-765.

Tyler, A. y V. Evans (2003): The Semantics of English Prepositions: Spatial Scenes, Embodied Experience and Cognition. Cambridge, Cambridge University Press.

Verschueren, J. (2000): "Notes on the role of metapragmatic awareness in language", Pragmatics, 10:4, págs. 439-456.

Verschueren, J. (2002): Para entender la pragmática. Madrid, Gredos.

Waltereit, R. (2006): "The rise of discourse markers in Italian: a specific type of language change”. En Fischer, K. (ed.), págs. 61-76. 
Wierzbicka, A. (1988): The semantics of grammar. Amsterdam/Philadelphia, John Benjamins.

Wierzbicka, A. (1996): Semantics. Primes and Universals. Oxford/New York, Oxford University Press. 